\title{
New Insights Into Microbiota Modulation-Based Nutritional Interventions for Neurodevelopmental Outcomes in Preterm Infants
}

\author{
Sylvie Buffet-Bataillon 1,2, Amandine Bellanger, ${ }^{1,3}$, Gaelle Boudry', \\ Jean-Pierre Gangneux ${ }^{4}$, Mathilde Yverneau ${ }^{3}$, Alain Beuchée ${ }^{5}$, Sophie Blat ${ }^{1}$ and \\ Isabelle Le Huërou-Luron ${ }^{1 *}$
}

1 Institut NuMeCan, INRAE, INSERM, Univ Rennes, Saint-Gilles, France, ${ }^{2}$ Department of Clinical Microbiology, CHU Rennes, Rennes, France, ${ }^{3}$ Department of Pediatrics-Neonatology, CHU Rennes, Rennes, France, ${ }^{4} \mathrm{CHU}$ Rennes, INSERM, Irset, UMR_S 1085, Univ Rennes, Rennes, France, ${ }^{5}$ Department of Pediatrics-Neonatology, Univ Rennes, CHU Rennes, LTSI-UMR 1099, Rennes, France

\section{OPEN ACCESS}

Edited by:

Anne-Judith Waligora-Dupriet, Université Paris Descartes, France

Reviewed by: Fabien Magne, University of Chile, Chile Roberto Di Marco, University of Molise, Italy

*Correspondence: Isabelle Le Huërou-Luron Isabelle.luron@inrae.fr

Specialty section: This article was submitted to Microbial Symbioses, a section of the journal

Frontiers in Microbiology

Received: 05 March 2021

Accepted: 12 May 2021

Published: 11 June 2021

Citation:

Buffet-Bataillon S, Bellanger A

Boudry G, Gangneux J-P, Yverneau M, Beuchée A, Blat $S$ and Le Huërou-Luron I (2021) New Insights Into Microbiota Modulation-Based Nutritional Interventions for Neurodevelopmental

Outcomes in Preterm Infants.

Front. Microbiol. 12:676622. doi: 10.3389/fmicb.2021.676622
Gut microbiota and the central nervous system have parallel developmental windows during pre and post-natal life. Increasing evidences suggest that intestinal dysbiosis in preterm infants predisposes the neonate to adverse neurological outcomes later in life. Understanding the link between gut microbiota colonization and brain development to tailor therapies aimed at optimizing initial colonization and microbiota development are promising strategies to warrant adequate brain development and enhance neurological outcomes in preterm infants. Breast-feeding has been associated with both adequate cognitive development and healthy microbiota in preterms. Infant formula are industrially produced substitutes for infant nutrition that do not completely recapitulate breastfeeding benefices and could be largely improved by the understanding of the role of breast milk components upon gut microbiota. In this review, we will first discuss the nutritional and bioactive component information on breast milk composition and its contribution to the assembly of the neonatal gut microbiota in preterms. We will then discuss the emerging pathways connecting the gut microbiota and brain development. Finally, we will discuss the promising microbiota modulation-based nutritional interventions (including probiotic and prebiotic supplementation of infant formula and maternal nutrition) for improving neurodevelopmental outcomes.

Keywords: microbiota, preterm, breast-feeding, infant formula, maternal nutrition in pregnancy

\section{INTRODUCTION}

The impact of the microbiota on mammalian development has been well documented with scientific evidence highlighting an association between gut microbiota and brain functions through the humoral and neural pathways of the gut-brain axis (Burokas et al., 2015; Cryan and Dinan, 2015). The intestinal microbiota is critical in the functional development of microglia, a key element 
in the prevention of neurodevelopmental and neurodegenerative diseases (Hazlett et al., 2005; Harry, 2013; Erny et al., 2015). As an example, modified levels of Firmicutes and Bacteroidetes were reported in the gut microbiota of children with autism (Finegold et al., 2010; Tomova et al., 2015). In addition, schizophrenia and attention-deficit hyperactivity disorders are associated with intestinal dysbiosis (Dinan et al., 2014; Cenit et al., 2017). The intestinal microbiota could affect brain physiology by modification of epigenetic modulation-based gene expression of genes associated with neuronal plasticity, learning, memory, and neurogenesis, as well as with behavioral disorders (Stilling et al., 2014; Majnik and Lane, 2015). Corroborating clinical research, animal studies have shown that germ-free mice exhibit disturbed social behavior and that brain morphological organization and development rely on gut microbiota composition (Diaz Heijtz et al., 2011; Desbonnet et al., 2014; Lu et al., 2018).

Survival of preterm babies has increased worldwide, with a concomitant reduction in severe neonatal morbidity. However, a recent evaluation of developmental and behavioral outcomes in a large French cohort of preterm infants, EPIPAGE, clearly highlighted that $40-50 \%$ (at 2 years of corrected age) and 19-28\% (at 5 years of corrected age) of neonates born at less than 32 weeks of gestational age displayed neurodevelopmental delays (Pierrat et al., 2017, 2020). This study corroborates other works reporting language difficulties up to 13 ears of age in children born preterm, with no evidence of developmental "catch-up" (Diaz Heijtz et al., 2011; van Noort-van der Spek et al., 2012; Nguyen et al., 2018) and disabilities such as school difficulties and behavioral problems that emerged into adolescence (Saigal and Doyle, 2008). Children with such delays may represent a group at risk for future academic difficulties and with poorer socialemotional competence although most of them recover well during their transition into adulthood (Saigal and Doyle, 2008). Moreover, an immature microbiota was associated with 2year non-optimal neurodevelopmental outcomes in preterm infants (Rozé et al., 2020). The goal of early perinatal intervention is therefore to reduce or prevent abnormal brain development. Recent studies revealed how maternal nutrition during pregnancy and nursing and infant formula feeding influenced both offspring microbiota and brain neurogenesis, and later cognitive and behavior (eating, social, locomotor, and exploratory) abilities (Ehrenkranz et al., 2006; Van Lieshout, 2013). Targeting the critical window of both gut microbiota and brain early development with personalized nutrition to apply potential neuroprotective strategies has potential therapeutic significance for preterm infants (Diaz Heijtz et al., 2011; Borre et al., 2014a,b).

In this review, we will describe the composition of preterm breast milk and infant formula for preterm infants, the development of the gut microbiota, and the neurodevelopment deficits associated with altered gut microbiota, and discuss potential new therapeutic strategies to restore microbiota and optimize neurodevelopment in preterm infants.

\section{COMPOSITION OF PRETERM INFANT FEEDING: BREAST MILK AND INFANT FORMULA}

\section{Human Milk Macronutrient Composition: Preterm vs. Term}

Adequate nutritional supply during the first weeks of life is critical for neurodevelopment and growth of preterm infants (Coviello et al., 2018). Breast milk is the optimal diet for term infants as well as for premature infants as early as their digestive system is mature for macronutrient digestion. Benefits of human milk (HM) to preterm neonates include improvements in host defense, digestion and absorption of nutrients, gut function and neurodevelopment, short-term protection against necrotizing enterocolitis (NEC) and better long term health outcomes (Bauer and Gerss, 2011). However, suboptimal weight gain and nutritional deficits may be observed in premature babies born at a gestational age below 28 weeks, due to their requirements for large amounts of protein and energy to achieve appropriate growth (European Society of Paediatric Gastroenterology and Nutrition Committee on Nutrition of the Preterm Infant, 1987; Agostoni et al., 2010; Joosten et al., 2018). HM fortification in energy, proteins and minerals is therefore recommended in routine nutritional neonatal care of preterm infants.

The average macronutrient composition of mature ( $>4$ weeks of lactation), term milk ranges approximately from 0.9 to $1.2 \mathrm{~g}$ protein/100 mL, 3.4 to $4.1 \mathrm{~g}$ fat/100 mL, and 6.2 to $7.4 \mathrm{~g}$ lactose/100 mL (Ballard and Morrow, 2013; Le Huërou-Luron et al., 2018). That of preterm milk after the 5 th week of lactation ranges from 1.0 to $2.0 \mathrm{~g}$ protein $/ 100 \mathrm{~mL}, 3.7$ to $4.5 \mathrm{~g}$ fat $/ 100 \mathrm{~mL}$, and $7.5 \mathrm{~g}$ lactose/100 $\mathrm{mL}$ (Bauer and Gerss, 2011; Gidrewicz and Fenton, 2014). It is noteworthy that recent metabolomic analyses of milk revealed that lactose and HM oligosaccharide (HMO) levels were significantly greater in preterm than in term milk collected 1-3 weeks postpartum (Sundekilde et al., 2016; Perrone et al., 2019). The metabolizable energy content of term and preterm milk ranges from 61 to 92 and 48 to $85 \mathrm{kcal} / 100 \mathrm{~mL}$, respectively, one-half provided by fat (Gidrewicz and Fenton, 2014). The macronutrient content of breast milk changes throughout the course of lactation. Both preterm and term colostrum has higher content of protein, but lower contents of energy, fat and lactose than mature milk (Bauer and Gerss, 2011; Gidrewicz and Fenton, 2014; Bulut et al., 2019). HM contains hundreds of bioactive molecules that considerably contribute to overall health benefits for neonates (Carr et al., 2021). Its composition in bioactive molecules changes between mothers in relation with the degree of prematurity, genetic and dietary factors.

\section{Protein Content in Preterm and Term Breast Milk (Figure 1)}

It is noticeable that milk produced by mothers who deliver prematurely has higher protein concentration during the first weeks of lactation than the milk of mother who delivered at term. A meta-analysis including forty-one studies on the nutrient content of preterm $(<37$ weeks of gestation) and 
term (37-42 weeks of gestation) 24-h collected HM reported up to $35 \%(0.7 \mathrm{~g} / 100 \mathrm{~mL})$ higher true protein content in preterm colostrum than term colostrum (Gidrewicz and Fenton, 2014). Also of importance, the inter-individual variability of the protein content in preterm milk in the first postnatal days is higher than in term milk (Gidrewicz and Fenton, 2014; Fischer Fumeaux et al., 2019). Thereafter, most of the differences in true protein between preterm and term milks were within $0.2 \mathrm{~g} / 100 \mathrm{~mL}$ with average protein concentration of $1.4 \mathrm{~g} / 100 \mathrm{~mL}$ and $1.2 \mathrm{~g} / 100 \mathrm{~mL}$ at 3-4 weeks of lactation, respectively. No more differences occurred beyond postnatal weeks 10-12. However, the previous longitudinal analysis of Bauer and Gerss (2011) reported substantially higher protein content values (Figure 1). More precisely, protein concentration differed by $0.19 \mathrm{~g} / 100 \mathrm{~mL}$ (average value on the first 8 weeks of gestation) in extremely preterm milk ( $<28$ weeks of gestation) vs. severely preterm milk (28-31 weeks of gestation), by $0.45 \mathrm{~g} / 100 \mathrm{~mL}$ in extremely preterm milk vs. moderately preterm milk (32-33 weeks of gestation), and by $0.73 \mathrm{~g} / 100 \mathrm{~mL}$ in extremely preterm milk vs. term milk (Bauer and Gerss, 2011).

Besides their critical importance in terms of nutrition and source of amino acids, proteins have potential effects on the developing microbiota of neonates. Although milk protein digestibility is very high, undigested dietary protein or fractions of these proteins, associated with endogenous proteins may be fermented by preterm gut microbiota (Boudry et al., 2016; Beverly et al., 2019). Indeed, for low birth weight piglets characterized with intestinal immaturity, the quantity of protein intake, specifically when fed formula with high protein level, induced sustained modifications of gut microbiota composition in the first and 5 months of age (Chatelais et al., 2011; Boudry et al., 2013).

Colostrum is rich in immunologic and developmental factors such as immunoglobulins (Igs), predominantly IgA, epidermal growth factor (EGF), TGF $\beta 1$, TGF $\beta 2$ and cytokines (IL-6, IL8, IL-10, IL-13, and $\mathrm{TNF} \alpha$ ), supporting the maturation of the neonatal intestine and its immune system. The decrease in immunologic component concentration observed during lactation was described to be dependent on gestational length (Castellote et al., 2011). The colostrum of preterm women (delivery between weeks 30 and 37 of gestation) was equal to or richer than that of term women (delivery between weeks 38 and 42 of gestation) for the above-mentioned immunologic factors. Conversely, the colostrum of very preterm women (delivery before week 30 of gestation) had lower contents in most of the immunologic factors than that of term women (Figure 1). HM is the main source of $\operatorname{IgA}$ for neonates as they produce very low amounts of IgA during the first 2 weeks of life. Therefore, after birth, HM composition doesn't allow effective immune defense for women with very preterm babies as opposed to women with preterm babies. At the end of the first month of lactation, immunologic factor concentrations were similar in the mature milk of women, whatever their gestational length, suggesting that only the colostral immunologic supply is dependent of childbirth date (Castellote et al., 2011).
Among proteins present in breast milk, some have antimicrobial properties including IgA, lactoferrin and lysozyme. IgA plays an essential role in defense against pathogenic bacteria but also in controlling gut microbiota composition. Indeed, selective IgA-deficiency in adult humans induced an altered gut microbiota composition (decreased bacterial diversity and changes in abundances of specific bacterial groups such as increased relative abundances of Proteobacteria, notably of the inflammatory facultative anaerobes Enterobacteriaceae, and of some taxa of the Ruminococcaceae family) as compared to adult healthy controls (Catanzaro et al., 2019). In healthy condition, a great proportion (24-74\%) of live bacterial cells is bound by IgA, reflecting a stable IgA response to commensal bacteria (Mantis et al., 2011). With the human commensal Bacteroides fragilis, it was demonstrated that IgA-bacteria interaction facilitated bacterial adherence to the gut mucosal surface and stable colonization of the gut through exclusion of exogenous competitors (Donaldson et al., 2018). The abundance of IgAbound bacteria was greater in fecal samples from breast-milk-fed infants compared to formula-fed infants (Gopalakrishna et al., 2019). Moreover, the importance of the maternal IgA-bacteria interaction in the protection against NEC in preterms was recently confirmed (Gopalakrishna et al., 2019). Indeed, a relative decrease in IgA-bound bacteria and an increasing dominance held by Enterobacteriaceae in the IgA-unbound fraction of the microbiota was associated with the development of NEC in preterm neonates. In addition, Igs which are $N$-glycosylated proteins may be a carbon source for gut bacteria such as Bacteroides that express carbohydrate-active enzymes involved in the degradation of glycans (Briliute et al., 2019).

Lactoferrin is another HM component that favors gut infant colonization with beneficial bacteria (Mastromarino et al., 2014). The amount of lactoferrin in feces in 1-month old infants was positively associated with the amount of lactoferrin in mature HM, confirming that HM represents the main source of lactoferrin in infant gut. A bifidogenic effect of lactoferrin was reported in vitro and in vivo in both neonatal pigs and human infant microbiota-associated mice fed bovine lactoferrin-fortified milk (Hentges et al., 1992; Hu et al., 2012) as well as in human infants after 3 months feeding with a lactoferrin enriched formula (Roberts et al., 1992). Lactoferrin concentration decreased during the first month of lactation in both full-term (36-41 weeks of gestation) and pre-term (26-36 weeks of gestation) milks with no significant differences between full-term and preterm milks (Mastromarino et al., 2014) (Figure 1). However, positive correlations between lactoferrin concentration and fecal Bifidobacterium and Lactobacillus were demonstrated at birth in preterm, but not term, neonates (Mastromarino et al., 2014). Therefore, lactoferrin may represent an important factor driving the composition of the neonatal gut microbiota particularly in preterm infants although its benefit in reducing mortality or significant neonatal morbidities in very low birth weight infants was not clearly demonstrated using bovine lactoferrin supplementation (Asztalos et al., 2020).

Lysozyme is present in breast milk at relatively high concentrations and degrades the outer cell walls of Gramnegative bacteria. Lysozyme content decreased progressively 

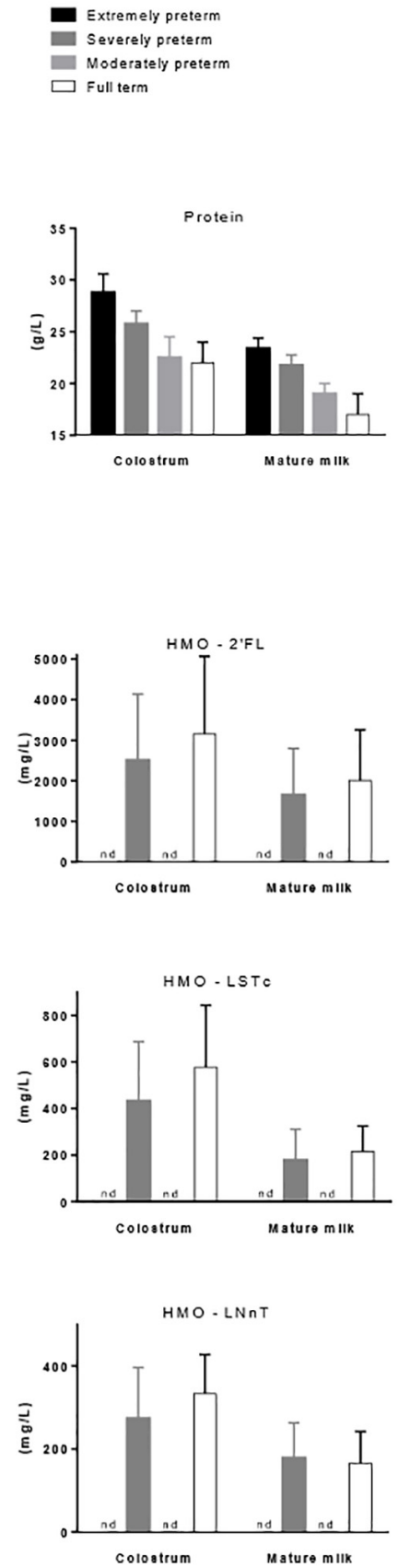
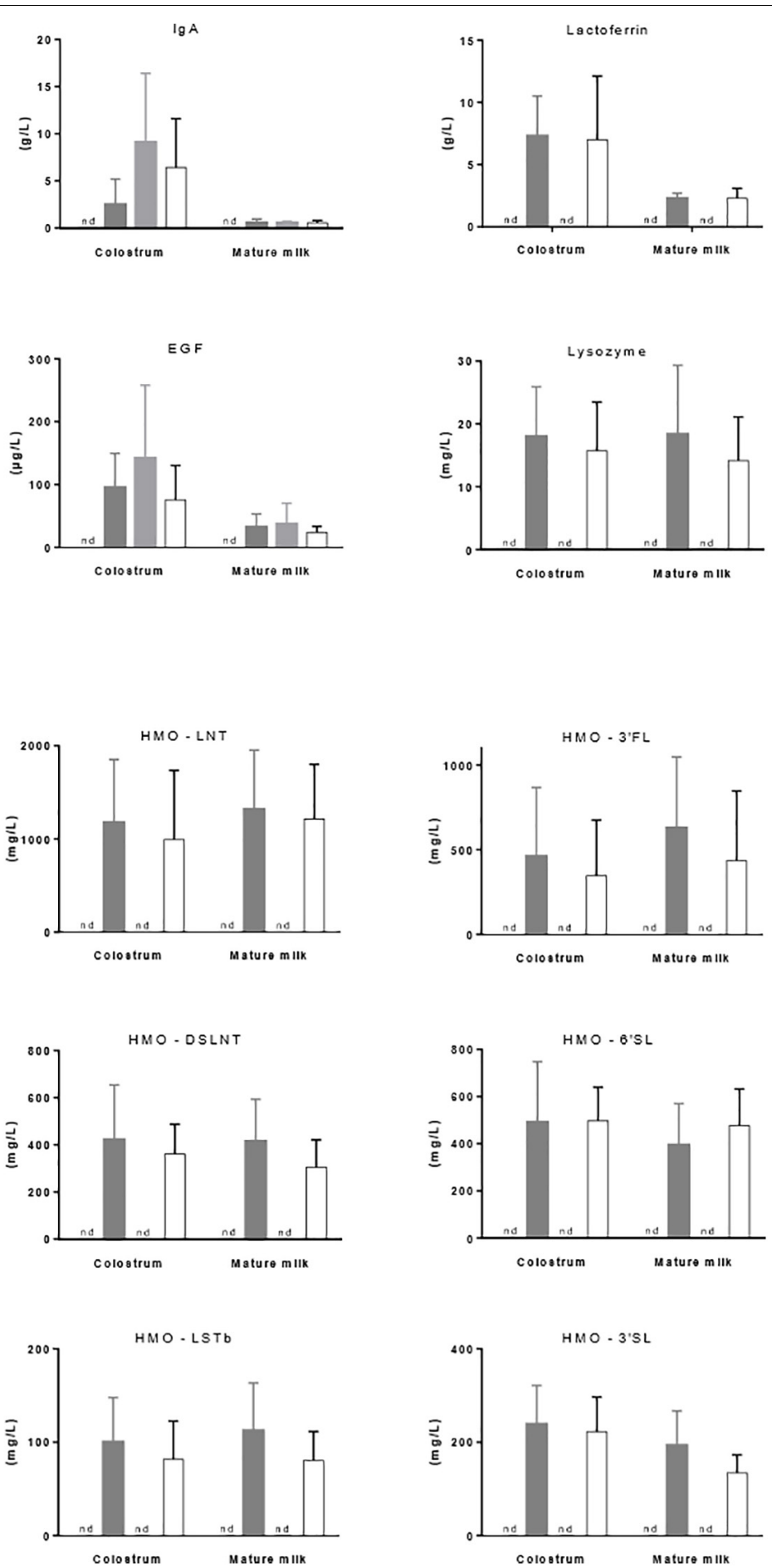

FIGURE 1 | Mean concentration ( $\pm S D$ ) of protein (Bauer and Gerss, 2011), IgA (Castellote et al., 2011), lactoferrin (Mastromarino et al., 2014), EGF (Castellote et al., 2011), lysozyme (Hsu et al., 2014), and nine prevalent forms of HMOs (Austin et al., 2019) in the colostrum (<7 days of lactation) and mature milk (1 month of lactation) of mothers that gave birth to extremely preterm (below 29 weeks of gestation), severely preterm (28-32 weeks, excepted for lactoferrin 26-36 weeks), moderately preterm (30-37 weeks) or full term (36-42 weeks) babies. nd, not determined.

during the first 2 weeks of lactation, without any major differences in relation to the gestational age at delivery (Montagne et al., 1999; Hsu et al., 2014).

\section{Lipid Content in Preterm and Term Breast Milk}

Dietary lipids are crucial for neonates to meet their high energy requirements but also numerous physiological functions critical 
to their growth and health. The anatomical and functional development of the brain depends particularly on the supply of long-chain polyunsaturated fatty acids (LC-PUFAs). Human milk fat provided in the form of globules consists mainly of $97 \%$ triglycerides (TAG), small amounts of mono- and diacylglycerides (MAG and DAG), around $1 \%$ of phospholipids and $0.5 \%$ of sterols, mostly cholesterol (Bourlieu et al., 2015). HM lipid specificity consists of over 400 fatty acids (FAs) with variable chain lengths and unsaturations, an esterification of palmitic acid primarily at the sn-2 position $(\sim 70 \%)$, unsaturated FAs mainly at the sn-1,3 positions and the high proportion of LC-PUFAs $[n-6$ (such as arachidonic acid, AA) and $n-3$ (such as eicosapentaenoic, EPA and docosahexaenoic acids, DHA), which are derived from the essential PUFAs linoleic acid (LA) and alpha-linolenic acid (ALA), respectively] (Le Huërou-Luron et al., 2018). The content in LA and ALA ranges from 10 to $24 \%$ of FAs and from 0.6 to $1.9 \%$ of FAs, respectively (Delplanque et al., 2015). Total milk fat and the essential PUFAs contents increase with milk maturation whereas the proportion of $n-6$ and $n-3$ LC-PUFAs decreases markedly by about $38 \%$ for AA and about $50 \%$ for DHA during the course of the first month of lactation (Koletzko et al., 2001). During the last trimester of gestation the supply of LC-PUFAs from maternal plasma to the fetus is actively provided by transfer across the placenta. Thus, in premature birth, the maternal FAs supply stops early and the preterm infant receives less amount of LC-PUFAs prior to birth than the full-term infant (Mazzocchi et al., 2018). Some studies reported slightly higher proportions of DHA and AA in preterm than term milk, but also of medium- and intermediatechain length FAs, which could support the higher LC-PUFAs requirement of preterms at birth (Lapillonne et al., 2013), but others reported lower levels of EPA and DHA in preterm milk (Berenhauser et al., 2012), while others did not find any difference between preterm and term milk (Granot et al., 2016). Shortand medium-chain FAs (butyrate, caprylate and caprate) were found in lower concentrations in preterm milk compared with term milk (Sundekilde et al., 2016). HM of women who gave birth prematurely displayed a deficiency in vitamins $\mathrm{A}$ and $\mathrm{E}$ (Sámano et al., 2017).

Very little is known about the influence of milk FAs on the gut microbiota. In vitro, medium-chain FAs and digestion products of sphingolipids demonstrated bactericidal activities against pathogens, suggesting a potential protection against foodborne gastroenteritis (Sprong et al., 2001). Moreover, mediumchain FAs were shown to modify gut microbiota in vitro (Nejrup et al., 2015), in piglets (Zentek et al., 2012) and germ-free mice (Nejrup et al., 2017). In infant formula, increasing the proportion of palmitate esterified in the sn-2 position resulted in higher Lactobacillus and Bifidobacterium counts in fecal stools of term formula-fed infants to a level similar to that of breast-fed infants (Yaron et al., 2013). A significant association between sn-2 FAs in milk and infant gut microbiota was confirmed in a Chinese human cohort, particularly between C10:0 to C18:0 FAs, LCPUFAs (AA and DHA) with Bacteroides, Enterobacteriaceae, Veillonella, Streptococcus, and Clostridium (Jiang et al., 2018). To our knowledge, such correlations in preterm milk have not been studied.
Beyond FA composition, the lipid matrix structure is also of great importance. HM fat is organized in its native form in dispersed globules enveloped by a tri-layer biological membrane called milk fat globule membrane (MFGM) which has been reported to provide a beneficial impact on human brain development, gut immunity and barrier functions in neonates when supplemented in infant formula (Timby et al., 2017b; Lemaire et al., 2018). MFGM composition is influenced by maternal factors and by the changing needs of the infant over the period of lactation (Lee et al., 2018), leading to the speculation that its composition may also change in preterm milk, although no data are currently available. Lipids, proteins and surface carbohydrate moieties in the MFGM might have an important role in profiling gut microbiota as thoroughly reviewed (Lee et al., 2018), although moderate effects have recently been observed on the oral microbiota of 4 month-old infants fed formula supplemented with a bovine MFGM concentrate compared to a standard formula (Timby et al., 2017a). Moreover, MFGM may influence protein digestion and consequently the protein digestion products that enter the colon, and by this way indirectly influence microbiota composition in the infant gut (Le HuerouLuron et al., 2018). Data on the impact of prematurity on MGFM composition are scarce. Levels of total phospholipids and gangliosides in HM appeared to be highest in colostrum. Higher sphingomyelin and lower or similar phospholipid compositions have been reported in preterm milk compared to term milk (Bitman et al., 1984; Shoji et al., 2006), but Maas et al. (2017) recently reported that $\mathrm{HM}$ concentration of choline-containing compounds, including phosphatidylcholine and sphingomyelin, were lower after preterm compared to term delivery. Intriguingly, phosphatidylcholine precursors, choline and phosphocholine, were found in higher levels in preterm milk than in full term milk (Sundekilde et al., 2016).

\section{Lactose and Human Milk Oligosaccharides (HMO) Content in Preterm and Term Breast Milk}

Human milk oligosaccharides include more than 200 different compounds and form the third-largest solid component in HM after lipids and lactose $(5.5-7.0 \mathrm{~g} / 100 \mathrm{~mL})$. Their concentration range from $2.5 \mathrm{~g} / 100 \mathrm{~mL}$ in colostrum and between 1.0 and $1.5 \mathrm{~g} / 00 \mathrm{~mL}$ in mature term milk (Kunz and Rudloff, 1993; Kunz et al., 1999). HMOs are complex glycans, non-hydrolyzed by gut digestive enzymes but a substrate for infant gut microbiota. HMOs prevent attachment of pathogens to the mucosa, as soluble decoy receptors for pathogens, and may reduce the presence of glycans expressed at the epithelial surface of the intestine (Kunz et al., 2000). HMOs also play roles in prevention of gut dysfunction. Specifically, lower breast milk content of disialyllacto- $N$-tetraose (DSLNT) which is linked with NEC prevention in neonatal rats, was associated with high NEC prevalence for human, as shown in a study of 200 American mothers with very low birth weight infants (birth weight under $1,500 \mathrm{~g}$ ) (Autran et al., 2018). It is noticeable that the pattern of oligosaccharides in HM is highly variable between mothers. The presence or absence of functional fucosyltransferase-2 (FUT2) and fucosyltransferase-3 (FUT3) enzymes depending on maternal genetic factors is known to significantly influence 
the HMO profile. The mother's Secretor and Lewis blood groups define four phenotypes: Lewis positive Secretors (FUT2 active, FUT3 active; Le+Se+), Lewis negative Secretors (FUT2 active, FUT3 inactive; $\mathrm{Le}-\mathrm{Se}+$ ), Lewis positive Non-secretors (FUT2 inactive, FUT3 active; $\mathrm{Le}+\mathrm{Se}-$ ) and Lewis negative Nonsecretors (FUT2 inactive, FUT3 inactive; $\mathrm{Le}-\mathrm{Se}-$ ), characterized by different levels of HMOs. Infants of secretor mothers (Le+Se+ or $\mathrm{Le}-\mathrm{Se}+$ ) may be protected by fucosylated HMOs that decrease the levels of pathogens associated with NEC and sepsis (Bering, 2018). In addition, higher levels of Proteobacteria and lower levels of Firmicutes were observed in preterm infants of non-secretor mothers (Underwood et al., 2015). Other factors including lactation stage, parity, mode of delivery, pre-pregnancy maternal body mass index may also play a significant role in HMO composition (Azad et al., 2018; Samuel et al., 2019).

Discrepancies exist in the literature related to the prematurity effect on HMO content, i.e., no change in HMO composition (Kunz and Rudloff, 1993; Nakhla et al., 1999; Gabrielli et al., 2011; Kunz et al., 2017; Autran et al., 2018), higher HMO content in preterm milk vs. term milk (Coppa et al., 1997; Sundekilde et al., 2016), especially the fucosylated ones (fucose, $\mathrm{N}$-acetyl-neuraminic and $\mathrm{N}$-acetyl-glucosamine) (Perrone et al., 2019), and more highly variable HMO composition in preterm milk (Nakhla et al., 1999; De Leoz et al., 2012). However, fucosylation of HMOs may not be as well-regulated in preterm milk as in term milk (De Leoz et al., 2012). A recent study described the dynamical evolution of HMO content of preterm and term milks in 53 mothers over the first four and the first two postnatal months of lactation, respectively (Austin et al., 2019) (Figure 1). Although the concentration of most HMOs was comparable at equivalent postpartum age, that of 3-sialyllactose (3'SL), DSLNT and Siallylacto- $N$-neo-tetraose b (LSTb) was higher and that of 6-sialyllactose (6'SL) and Siallylacto- $N$-neo-tetraose c (LSTc) was lower in preterm than term milk. Furthermore, lacto- $N$-neotetraose concentration was shown to significantly decrease in term milk over time but did not significantly change in preterm milk (Spevacek et al., 2015). Interestingly, however, a study documenting the changes in metabolomic profile of preterm and term milks highlighted that the preterm milk metabolome changed within 5-7 weeks postpartum to resemble that of full-term milk (Sundekilde et al., 2016). The effect of HMO content on neonatal microbiota agrees with a highly selective prebiotic effect of HMOs that shape the gut microbiota in the first weeks of life (Spevacek et al., 2015). Indeed, the primo-colonization of the intestine with bacterial populations composed primarily of non-HMOconsuming Enterobacteriaceae and Staphylococcaceae resulted in an increase of fecal HMOs when the further higher proportion of HMO-consuming Bacteroidaceae and Bifidobacteriaceae was associated with a reduction in fecal HMOs (De Leoz et al., 2015).

\section{Bacteria and Fungi Content in Preterm and Term Breast Milk}

The discovery of a HM microbiota, from the 2000s, has led many teams to question its origin and its relative role, compared to other microbiota (particularly maternal fecal microbiota), in the gut colonization of the newborn. HM guarantees a constant supply of bacteria throughout the lactation period, values ranging from $10^{2}$ to $10^{4}$ bacterial cells $/ \mathrm{mL}$ with a culture-dependent analysis and around $10^{6}$ bacterial cells $/ \mathrm{mL}$ with a qPCR-based analysis (Jost et al., 2013; Boix-Amorós et al., 2019). As reported in extensive reviews (Fitzstevens et al., 2017; Oikonomou et al., 2020), HM microbiota is a diverse and complex community with Streptococcus and Staphylococcus as the dominant genera in most of the studies using either culture-independent or culture-dependent approaches. Propionibacterium, Bifidobacterium, Bacteroides, Enterococcus, Lactobacillus, Acinetobacter, and Veillonella are, among others, the most cited dominant taxa in HM. Strong interindividual variations exist that may be explained by several host and environmental factors including maternal body mass index, diet, time of lactation, ethnicity as well as geographical location (Gomez-Gallego et al., 2016; Kumar et al., 2016). Only one study investigated the effects of stages of gestation on milk microbiota from 39 Caucasian Canadian women (Urbaniak et al., 2016). No significant difference in the microbial profiles of milk between preterm and term births was observed. More studies are still needed with larger samples sizes to better assess whether stages of gestation impact milk microbiota composition.

Only limited data are available on the quantitative and qualitative fungal load of human breast milk compared to animal milks. Using multiple approaches, from culture to molecular techniques, Boix-Amorós et al. (2017) showed that $89 \%$ of samples had detectable levels of fungal DNA (median load of $3.5 \times 10^{5}$ cells $/ \mathrm{ml}$ ). The three more abundant yeast genera found were Malassezia, Candida, and Saccharomyces. At the species level, yeast species detected by pyrosequencing and/or culture were both typical yeasts from the skin and/or oral cavity, such as Malassezia globosa, Malassezia restricta, Candida parapsilosis, Candida albicans, Yarrowia lipolytica, Saccharomyces cerevisiae, or Rhodotorula mucilaginosa. Filamentous fungi were also detected, and the most prevalent were Alternaria and Cladosporium species. More recently, a high-throughput approach using next generation sequencing allowed to characterize the human milk mycobiome from various countries and continents (Boix-Amorós et al., 2019). Basidiomycota (58.65\%) and Ascomycota (41.03\%) account for the most important phyla. Malassezia, Davidiella, Sistotrema, and Penicillium were the four more abundant genera detected.

\section{Pasteurized Human Donor Milk}

The World Health Organization recommends pasteurized human donor milk for preterm infants when the mother's own milk is unavailable (World Health Organization, 2011). In preterm and low birth weight infants, evidences may indicate that feeding with human donor milk, either as a supplement to maternal expressed breast milk or as a sole diet resulted in a lower risk of developing NEC compared with formula (Quigley et al., 2019). Although human donor milk feeding was associated with lower rates of weight gain, growth, and head growth, no effect of milk feeding types on all-cause mortality, long-term growth and neurodevelopment has been observed. The inactivation of milk bacteria and the significant reduction of bioactive proteins and enzymes resulting from the pasteurization process of the human 
donor milk may limit some of its health benefit compared to a mother's own milk. Indeed, bioactive components such as Igs, lactoferrin, enzymes (lipase), HMOs and vitamins are reduced or inactivated after pasteurization. In addition, pasteurization associated to freeze-thaw cycles may modify the kinetics of digestion of proteins and lipids by selectively modulating the intestinal release of amino acids and decreasing that of some fatty acids as demonstrated using an in vitro dynamic digestion system (de Oliveira et al., 2016). However, it is noticeable that pasteurized HM favored an intestinal microbiome in infants more similar to mother's own milk than formula despite the differences in bacterial content between raw and pasteurized breast milks (Parra-Llorca et al., 2018). All these data suggests that the pasteurization of HM preserves most of functionalities of breast milk in terms of influence on the intestinal microbiota profile and health outcomes in preterm infants.

\section{Fortified Milk for Preterms}

Evidence indicates that HM is the best nutritional standard for infants that suits not only to term but also to preterm infants, especially those born with a very low birth weight (VLBW), conferring both short and long-term health benefits (Tudehope, 2013). However, HM does not meet the higher nutritional requirements of preterm and VLBW infants compared to those of term infants (Ballard and Morrow, 2013; Simpson et al., 2016) when fed at the usual feeding volumes during the first weeks of life. This may lead to postnatal growth restriction with the associated risk of impaired neurodevelopment and other poor health outcomes (Chan et al., 2016; Guellec et al., 2016; Coviello et al., 2018). Nutrient requirement of preterm infants is defined as intakes that enable the neonate to grow at the same rate as a fetus (Ziegler, 2014). Any shortfall in protein supply affects early growth of preterm infants and increases the risk for inadequate growth during later childhood and adulthood (van Beek et al., 2020). Thus, protein supply needs special attention in early life with the aim to meet the protein requirement of growing preterm infants ranging between 3.5 and $4.5 \mathrm{~g} / \mathrm{kg} /$ day (Agostoni et al., 2010; Ziegler, 2014). However, feeding with $150 \mathrm{~mL} / \mathrm{kg} /$ day of unfortified HM (often considered full enteral feeding) provides only about $1.8 \mathrm{~g} / \mathrm{kg} /$ day of protein. Optimal early nutrition of preterm infants is thus facilitated by using multi-nutrients human milk fortifier (MF) that increases the concentration of nutrients to their requirement levels at the recommended feeding volumes $(135-200 \mathrm{ml} / \mathrm{kg} / \mathrm{d})$ (Ziegler, 2011). HM fortification is now commonly recommended in neonatal intensive care units (NICU) of very preterm infants with a birthweight $<1,800 \mathrm{~g}$ (Moro et al., 2015). HM should be fortified with the nutrients in short supply, particularly with proteins, minerals such as calcium and phosphate, as well as micronutrients such as iron, zinc, copper, selenium and iodine (Arslanoglu et al., 2019). MF can be used safely as soon as the milk volume reaches 50$80 \mathrm{ml} / \mathrm{kg} / \mathrm{d}$. In contrast, no strong evidence supports the use of hydrolyzed protein source in MF (Arslanoglu et al., 2019). MF are commonly derived from bovine milk. In fact, fortification of breast milk feeds with human MF in comparison with bovine MF did not reduce the risk of necrotizing enterocolitis in preterm infants (Premkumar et al., 2019). Moreover, current data do not provide guidance on the optimal time to start fortification (Alyahya et al., 2020). Among the different fortification approaches, while "Standard fortification" falls short in supplying sufficient proteins, current recent data encouraged the use of "Individualized Fortification" (adjustable and targeted fortification) to optimize nutrient intake (Arslanoglu et al., 2019).

\section{Impact of Maternal Nutrition on Human Milk Quality}

Maternal nutrition may influence breast milk composition in mothers who delivered prematurely (Hascoët et al., 2019). However, only overall maternal carbohydrate intake was positively correlated with milk protein, fat and caloric density as observed in a French cohort of 81 mothers who delivered prematurely (between 24 and 34 weeks' gestational age), regardless of the kind of carbohydrate: sugar, fibers, or overall carbohydrates (Hascoët et al., 2019). The absence of effects of overall protein intake on the milk composition corroborated findings in mothers who delivered at term, such as the study by Zhao et al. (1989) in two Chinese cohorts from 2 areas of China differing in the mothers' overall protein intake, where no differences in 18 studied amino-acids could be find in breast milks. However, in a recent study with 220 Chinese lactating women who delivered at term, dietary patterns with high intake of red meat, cereals and eggs was associated with higher protein, total dry matter and energy content in $\mathrm{HM}$ (Huang and $\mathrm{Hu}$, 2020). Regarding lipids, supplementation of maternal diet with the $n-3$ PUFA precursor ALA did not modify the milk overall lipid concentration but qualitatively increased the proportion of ALA, still in mothers who delivered at term (Mazurier et al., 2017). Similarly, Chilean women who had a low intake of foods that are natural sources of $n-3$ PUFAs (vegetable oils, fish, and seafood) and a high intake of n-6 PUFAs (LA and AA) during lactation displayed a significant reduction of DHA levels in breast milk (Barrera et al., 2018). Interestingly, the concentration of $n-3$ PUFAs in HM would be related to the mothers' habitual but not current intake (Bzikowska-Jura et al., 2019), suggesting that current post-partum n-3 PUFA intake does not translate directly into their concentration in HM but is rather influenced by the maternal body stocks of FA. Pre-pregnancy obesity was associated with increased fat and energy content in HM 6 weeks after preterm delivery, which may be due to higher blood triglycerides in the obese or to oxidative stress and inflammation caused by obesity, with consequences for HM metabolomic profile (Burianova et al., 2019). A negative correlation between mother's weight and cholesterol concentration in HM has been described (Kamelska et al., 2012). The dietary intake of polyamines was significantly associated with the polyamine content of transitional HM collected in mothers who delivered prematurely, especially for spermidine and putrescine (Atiya Ali et al., 2014). Furthermore, total polyamine level was higher in preterm milk, with the levels of putrescine and spermidine being 50 and 25\% higher, than in term milk (Plaza-Zamora et al., 2013; Atiya Ali et al., 2014). The impact of maternal diet on HMO content has not been clearly addressed so far. Azad et al. (2018) found no association between overall diet quality and HMO 
concentration. However, maternal probiotic supplementation during late stages of pregnancy was recently associated with change in breast milk HMO composition (Seppo et al., 2019). Moreover HMO diversity and the concentration of LNnT were negatively correlated to prepregnancy body mass index, whereas 2'FL was positively associated to prepregnancy body mass index in secretor mothers, in a Finish cohort including both term and preterm-delivered women (Lagström et al., 2020). HM from obese women displayed increased levels of monosaccharides and sugar alcohols including mannose, ribose, lyxose, lyxitol (Saben et al., 2020) and Berger et al. (2018) revealed that mothers who consumed a beverage sweetened with high-fructose corn syrup had increased fructose in HM.

In a recent study, which specifically addressed the effect of maternal nutrition on HM microbiome, Babakobi et al. (2020) found a significant negative correlation between Streptococcus relative abundance in HM and maternal intake of PUFAs and folic acid, as well as with HM oleic acid content. Additional correlations were detected between Staphylococcus hominis and two MCFAs (C8:0 and C12:0) (Babakobi et al., 2020).

\section{GUT MICROBIOTA IN PRETERM INFANTS AND IMPACT OF ENVIRONMENTAL FACTORS}

\section{Initial Bacterial and Fungal Colonization: Preterm vs. Term Infants}

Recent articles showed bacterial presence in the amniotic fluid, umbilical cord and the placenta (Wassenaar and Panigrahi, 2014). While these observations suggest that colonization of the fetal gut may begin in utero, several other studies have put forward arguments against such a possibility (Salter et al., 2014; Lauder et al., 2016; Perez-Muñoz et al., 2017). The first meconium is rich in genera such as Escherichia-Shigella, Enterococcus, Leuconostoc, Lactococcus, and Streptococcus (Gomez-Gallego et al., 2016). Initial colonizing fungal species are also present in $71 \%$ of infants and include C. albicans and C. parapsilosis (Kaufman et al., 2006). At birth, the infant gut is an aerobic environment, which gradually becomes anaerobic over a period of days (Johnson and Versalovic, 2012; Jost et al., 2012). The meconium facultative aerobic bacteria that firstly colonize the infant gut (Escherichia and Enterococcus) eventually establish an anaerobic environment, and promote the colonization with obligate anaerobes, including Firmicutes such as Clostridia, Bacteroidetes, and especially the protective Bifidobacteria (Mackie et al., 1999). Bifidobacteria comprise the largest group within the infant microbiota (Jost et al., 2012; Jakobsson et al., 2014). Throughout this succession of organisms, the microbiota increases in diversity (Koenig et al., 2011; Jakobsson et al., 2014). At the opposite, gastrointestinal fungi are present at a significantly higher diversity during the first 3 months of life than later in life (Kaufman et al., 2006).

The microbiota development of infant gut is dependent on gestational age at time of delivery and, for term infants, mode of delivery (Dominguez-Bello et al., 2010; Makino et al., 2013; La Rosa et al., 2014). Term infants born vaginally are initially colonized by microbial communities resembling maternal vaginal microbiota (Lactobacillus, Prevotella, Candida, Davidiella and Cladosporium). In contrast, fecal microbiota of term infants delivered by cesarean section more closely resembles the skin microbiota (Staphylococcus, Propionibacterium, and Malassezia) (Dominguez-Bello et al., 2010; Nagata et al., 2012; Drell et al., 2013). Contrarily, the mode of delivery does not appear to significantly affect the initial colonizing community in preterm infants, which instead is hypothesized to be highly influenced by the environment (Schwiertz et al., 2003; Brooks et al., 2014). For preterm infants (gestational age $<33$ weeks) the early gut microbiota composition resembles bacterial communities colonizing hospital surfaces and feeding and intubation tubing and are enriched in Staphylococcus epidermis, Klebsiella pneumoniae, and Escherichia coli (Brooks et al., 2014). Preterm infants were also shown to be colonized early with C. albicans for a median range of 3 weeks and C. parapsilosis for 4 weeks (Kaufman et al., 2006). The examination of the gut-associated microbiota of 11 extremely low birth weight preterm infants in the first postnatal month revealed that the most prevalent and abundant fungi were Saccharomyces (S. cerevisiae) followed by Candida (C. albicans, Candida glabrata, C. parapsilosis, Candida tropicalis, Candida Diddensiae, and Candida quercitrusa) (LaTuga et al., 2011). The susceptibility to Candida invasive infection has been correlated with a naïve immune system, a bacterial dysbiosis and use of parenteral nutrition (Kumar et al., 2016).

Following initial colonization, gut microbiota of both term and preterm infants increases in diversity and dynamically changes in composition. However, specific bacterial succession patterns are unique to these two populations (Schwiertz et al., 2003; Yatsunenko et al., 2012; La Rosa et al., 2014). The most notable difference concerns the enrichment in Proteobacteria before 2 weeks of age in preterms. The developing term infant gut microbiota is initially dominated by Firmicutes, when Proteobacteria species are sparsely present in the first week of life and persist as minor components $(<10 \%$ relative abundance on average) throughout the first 2.5 years of life (Koenig et al., 2011). Thereafter there is an increase in Bifidobacterium and Bacteroides in healthy term infants within the first 6 months of life (Jost et al., 2012; La Rosa et al., 2014; Korpela et al., 2018). In contrast, preterm infant gut microbiota is quickly dominated by Proteobacteria (facultative anaerobes) species within the first week of life, which remain at high levels ( $>75 \%$ relative abundance on average) throughout the first month (Morowitz et al., 2011; La Rosa et al., 2014). Because of a prolonged dominance of Proteobacteria such as Enterobacteriaceae, preterm infants have a delayed progression to a Bifidobacteriumdominated (obligate anaerobes) microbiota compared to term infants (Butel et al., 2007; Bäckhed et al., 2015; Korpela et al., 2018). Overall, the intestinal microbiota from preterm infants up to 5 weeks of age clusters distinctly from that of full-term breastfed infants and the microbial patterns converge toward that of full-term breastfed infants only at or after 6 weeks of age (Claud et al., 2013). By the end of the first year of life, the infant gut microbiota begins to resemble an adult-like microbiota, reaching full maturity by 2-3 years of age (Palmer et al., 2007; Koenig 
et al., 2011; Yatsunenko et al., 2012). At 1 year of age, the infant gut microbiota has a characteristic abundance of Akkermansia muciniphila, Bacteroides, Veillonella, Clostridium coccoides, and Clostridium botulinum (Alou et al., 2016) and is dominated by three bacterial phyla: Firmicutes (Lachnospiraceae and Ruminococcaceae), Bacteroidetes (Bacteroidaceae, Prevotellaceae, and Rikenellaceae), and Actinobacteria (Bifidobacteriaceae and Coriobacteriaceae). These data demonstrate that while the succession of bacteria at the genus level is similar, dominance is different between preterm and term infants in the early period of life (Figure 2).

It is noteworthy that the severity of prematurity seems to be a major driver in the development of the microbiota for preterm infants, specifically the slowest rate of assembly was found in the most premature infants (between 25 and 30 weeks of gestational age) (La Rosa et al., 2014; Dahl et al., 2018; Korpela et al., 2018). The preterm infant microbiota may follow an age-dependent maturation which may be slightly dependent on a specific gestational age (Claud et al., 2013). The microbial community differences between preterm and term infants are due to differences in the environment of NICU as abovementioned, but also to an immaturity in the intestinal epithelium (Claud et al., 2013).

\section{Bacterial and Fungal Profiles of Preterm Infant Feces Associated With Breast Milk and Formula Feeding}

Whether the term infants are breastfed or formula-fed affects their gut microbiota (O'Sullivan et al., 2015; Boudry et al., 2021). Breast-fed term infants generally become colonized in the first weeks after birth with the protective bacterial Bifidobacterium and Lactobacillus that are able to consume HMOs whereas formula-fed infants have a higher diversity and levels of Enterobacteria, Clostridia, Bacteroides, Enterococcus, and Streptococcus (Favier et al., 2002; Penders et al., 2006; Bezirtzoglou et al., 2011; Azad et al., 2013; Bäckhed et al., 2015). Even if formula-fed infant harbor Bifidobacterium in their gut microbiota, breastfed infant gut is generally colonized with a more complex and diverse Bifidobacterium ecosystem and a twofold higher number of Bifidobacterium cells compared to formula-fed infants (Roger et al., 2010; Bezirtzoglou et al., 2011). In preterm infants, the impact of HM feeding on infant gut microbiota is not clearly assess due to the low numbers of preterm infants exclusively breastfed and the various timings in which formula feeding is introduced exclusively or in supplementation observed in clinical studies (Dahl et al., 2018). Indeed, preterm infant gut microbiota is enriched in microbes that commonly dominate in the presence of antibiotics (Wandro et al., 2018). However, vaginally born, exclusively breastfed preterm infants not exposed to antibiotics had fewer Firmicutes and more Proteobacteria than children born at term (Dahl et al., 2018). Preterm infants fed infant formula had a lower initial bacterial diversity and a less gradual increase in diversity compared to preterm infants who were fed HM (Gregory et al., 2016). Furthermore, the microbiota of preterm infants fed HM clusters regardless of birth weight, when that of preterm infants fed infant formula clustered differently based on birth weight (Gregory et al., 2016). The ordered succession of microbial taxa observed in HM-fed preterm infants was disrupted in those fed infant formula (Gregory et al., 2016). Fecal microbiota of preterm infants fed with exclusive own mother's HM presented increased richness compared to those fed with different proportions of formula. In addition differences in microbiota composition were reported: the mean proportion of Escherichia and Clostridium was always greater in preterm infants who received diets containing formula than in preterm infants fed with HM only (Zanella et al., 2019). It was also shown in a cohort of 3,161 preterm infants that a slow rate of progression of enteral feeding and a less favorable direct-breastfeeding policy was associated with colonization by Clostridium neonatale and/or Staphylococcus aureus and most likely with the increased risk of developing NEC (Rozé et al., 2017). The type of diet of the infant (formula-fed or breast-fed) does not seem to impact oral fungal profile, although fungi are present in HM (Boix-Amorós et al., 2019).

\section{Antibiotic, Antifungal, and Disinfectant Exposure (Environmental Factors) and Microbial Profiles}

\section{Antibiotics}

The composition of gut microbiota can be affected by the timing, duration, and type of antibiotic exposure (class, dose, period of exposure, pharmacological action, and targeted bacteria) in both preterm and term infants (Fouhy et al., 2012; Gasparrini et al., 2016; Gibson et al., 2016; Yassour et al., 2016; Iizumi et al., 2017). Specific properties of antibiotics such as antimicrobial effects or mode of action select intestinal bacteria and induce shifts in bacterial composition during antibiotic therapy (Pérez-Cobas et al., 2013). Intrapartum antibiotic prophylaxis induced lower gut diversity and abundance of Lactobacillus and Bifidobacterium in neonates (Mueller et al., 2015).

In preterm infants, meropenem, cefotaxime, and ticarcillinclavulanate are associated with significantly reduced species richness. In contrast, vancomycin and gentamicin, the antibiotics most commonly administered to preterm infants, have nonuniform effects on species richness (Gibson et al., 2016). In term infants, parenteral ampicillin and gentamicin administration (within $48 \mathrm{~h}$ of birth) resulted in a significantly increased abundance of Proteobacteria and decreased abundance of Actinobacteria (particularly Bifidobacterium) and Lactobacillus 4 weeks after the treatment compared to the untreated controls (Fouhy et al., 2012).

\section{Antifungals}

Preterm or VLBW infants have been identified as a high risk group of patients to be colonized with fungi and further to develop invasive fungal infections (Manzoni et al., 2015). The high mortality of these infections mainly due to Candida sp. conducted to the implementation of a randomized clinical trial to evaluate the performance of prophylactic administration of fluconazole during the first 6 weeks of life (Kaufman et al., 2001). Results showed that prophylaxis with fluconazole was effective in decreasing fungal colonization and preventing invasive fungal 

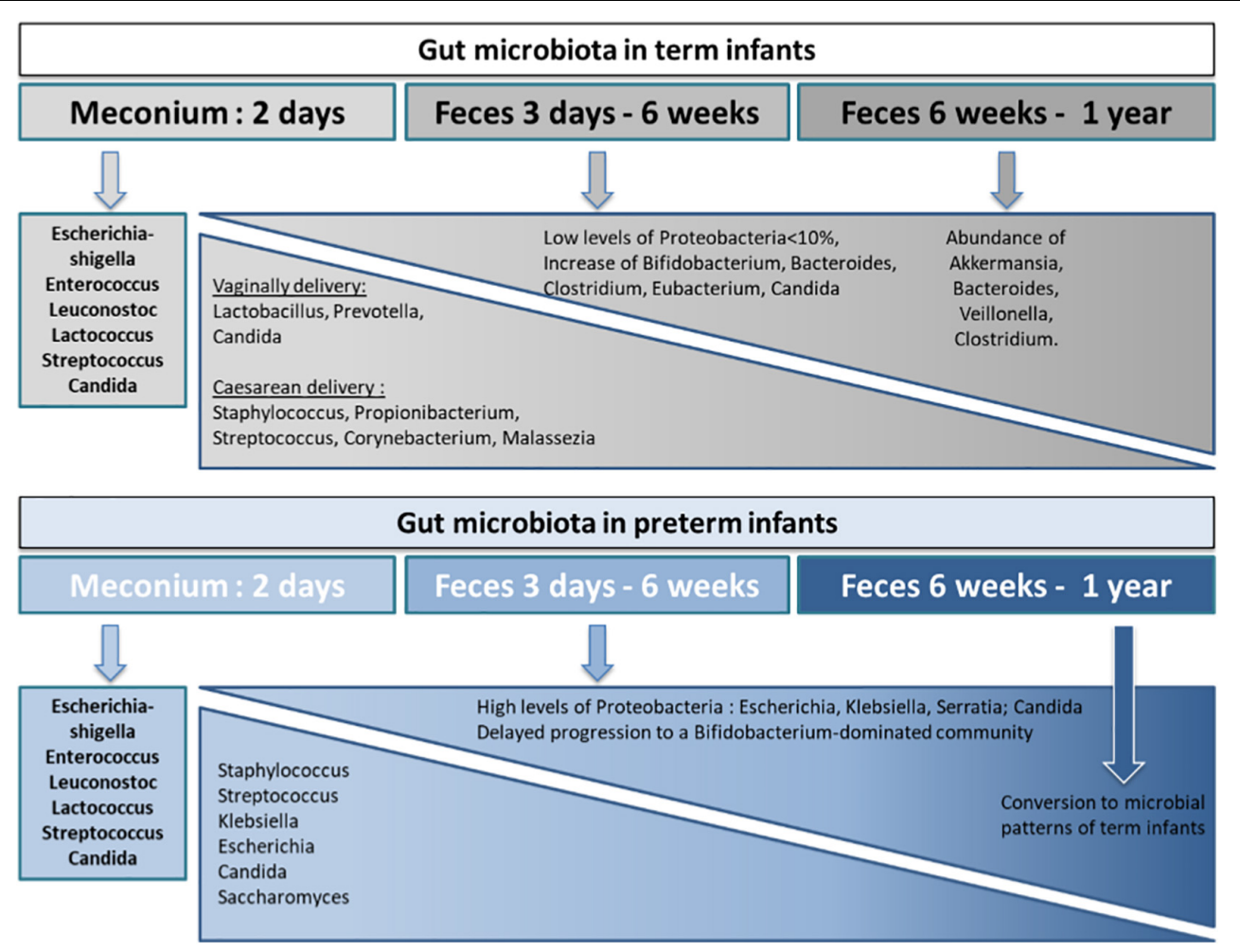

FIGURE 2 | Key bacterial and fungal colonization of the term and preterm infant gut microbiota from birth through 1 year of life. The composition of the gut microbiota in term and preterm infants varies differently from birth before reaching an identical composition at the first year of life. During the first year of life, pro-inflammatory colonizers are more present in preterm infants than in term infants. The developing term infant gut microbiota is initially dominated by Firmicutes, with low levels of Proteobacteria species, following by an increase in Bifidobacterium and Bacteroides within the first 6 months of life. In contrast, preterm infant gut microbiota is quickly dominated by Proteobacteria species within the first week of life, which remain at high levels throughout the first month and thus induce a delayed progression to a Bifidobacterium-dominated community compared to term infants. In the case of a vaginal delivery, early colonizers originate from the mother's vaginal and fecal microbiota whereas for C-sections, early colonizers belong to the environment of birth and the mother's skin microbiota. The gut microbiota differences between vaginally and caesarean delivery disappear after the first year of life.

infection in VLBW infants. It is noticeable that fluconazole prophylaxis did not induced non-albicans species selection nor emergence of fluconazole -resistant strains in a wide Italian study in preterm neonates in NICU over a 16-year surveillance period (Luparia et al., 2019) compared to hematological patients. However, despite the administration of antifungals, fungal colonization still occurred in 7 out of 11 extremely low birth weight infants (LaTuga et al., 2011). Although antibiotics do not directly act on fungi, anti-bacterial antibiotic exposure is associated with an increased rate of fungal colonization (Dollive et al., 2013). In preterm infants, exposure to cephalosporins is associated with an increased risk for invasive candidiasis (Kelly et al., 2015). The aerobic growth of C. albicans has been studied extensively. Interestingly the facultative anaerobic growth has been showed in vitro (Dumitru et al., 2004). This anaerobic growth of $C$. albicans may contribute to the resistance of $C$. albicans biofilms to antifungal drugs.

\section{Disinfectant}

A strong link has been shown between NICU-specific taxa and their presence in the gut microbiota of preterm infants, mostly mediated by healthcare providers and cleaning protocols (Brooks et al., 2018). Therefore, approaches that aim to change NICU microbiota may be an effective way to manipulate the early microbiota of preterm infants.

To summarize, the early window for gut microbiota establishment is critical. Gestational age, mode of delivery as well as environmental factors (antibiotic, antifungal, and disinfectant) largely affect gut microbiota establishment. However, nutrition also shapes the assembly of infant gut microbiota with significant functional implications (Fragkou et al., 2021).

\section{DYSBIOSIS, BRAIN DEVELOPMENT AND NEURODEVELOPMENTAL OUTCOMES}

\section{Post-natal Development of the Brain}

The brain undergoes a rapid trajectory of growth during the third trimester of gestation, with a $140 \%$ volume increase from the 30th to the 40th week of gestation, resulting in a neonatal brain representing about $36 \%$ of the adult volume at full-term birth. Brain structure and function continue to mature during the early post-natal life to reach $80-90 \%$ of the adult brain volume by the age of 2 (Knickmeyer et al., 2008). During this period, dendrites, 
axons, new synapses and glia cells expand, and myelination occurs. During the first two postnatal years, synapse production occurs with a peak between 3 and 24 months depending on the cortical region (Huttenlocher and Dabholkar, 1997). Synaptic refinement and elimination as well as myelination continue in late childhood and beyond adolescence (Petanjek et al., 2008). Prefrontal regions are among the last brain areas to reach mature levels (Giedd, 2004). Interestingly, magnetic resonance imaging (MRI) studies reveal that despite normal head circumference at birth, autistic children display abnormal regulation of brain growth resulting from early overgrowth followed by abnormally slowed growth (Courchesne et al., 2001; Hazlett et al., 2005) highlighting that adequate, i.e., not too slow but not too rapid, growth is a key parameter for later brain health.

In preterm infants, brain growth is a major matter of concern. Larger total brain tissue, white matter, and cerebellar volumes at term-equivalent age are associated with better neurodevelopment in very, moderate or late preterm children (Cheong et al., 2016; Schneider et al., 2018). Impaired neuronal connectivity, likely associated with impaired dendritic growth and synapse formation, was also observed in preterm infants during infancy and beyond, correlating with lower neurodevelopmental scores in adolescence (Constable et al., 2008; Dean et al., 2014). Despite intensive research and refinement of methods, the mechanisms leading to normal brain growth and maturation during the postnatal life are still not fully understood, especially in preterm infants. The role of environmental factors such as nutrition has been described (Schneider and Garcia-Rodenas, 2017). However, microbiota is another potentially key actor that starts to emerge.

\section{Evidences for a Role of the Microbiota in Neonatal Brain Development Evidences From Preclinical Models}

The germ-free (GF) mouse model has been widely used as a first approach to demonstrate the role of microbiota on brain development and function. These mice display decreased anxietylike behavior compared to conventional mice at adulthood and numerous alterations at the brain level (Luczynski et al., 2016). Indeed, compared to conventional mice, GF mice exhibit many brain alterations: higher expression of synaptic-related proteins (synaptophysin and PSD-95) in the striatum (Diaz Heijtz et al., 2011), increased levels of key myelin-associated genes and hypermyelination in the prefrontal cortex (Hoban et al., 2016), increased hippocampal cell survival (Ogbonnaya et al., 2015), reduced subventricular zone cell proliferation (Sawada et al., 2018), increased blood-brain-barrier permeability (Braniste et al., 2014), impaired microglia immune response and immature morphology (Erny et al., 2015), altered hippocampal microRNA and mRNA expression (Zhou et al., 2019), increased expression of splicing factors upon stimulation in the amygdala (Sawada et al., 2018; Stilling et al., 2018), decreased expression of the total brain-derived neurotrophic factor (BDNF) in the amygdala (Arentsen et al., 2015), and numerous alterations in neurotransmitter and receptor expression (Luczynski et al., 2016). Collectively, these data indicate a role of the microbiota on brain function, and especially on processes that are activated during brain post-natal maturation. Interestingly, most, but not all, of these alterations can be corrected upon colonization of GF mice at weaning. This both-ways reversible effect suggests that it may be possible to counterbalance such effects in certain conditions.

Beside GF models, early life intervention on gut microbiota in preclinical models also demonstrated long-term effect of neonatal dysbiosis on behavior. Indeed, oral administration of antibiotics (ampicillin or a cocktail of neomycin, bacitracin, and pirimacin) to pregnant mice leads to modification in motor activity of their offspring and altered social behavior, but only in the male offspring (Arentsen et al., 2017). Low-dose penicillin from late pregnancy until weaning decreased anxietylike behavior in young adult male mice (Leclercq et al., 2017). Interestingly, concurrent supplementation with a probiotic strain (Lactobacillus rhamnosus JB-1) prevented some of these alterations (Leclercq et al., 2017). Moreover, neonatal antibiotic treatment (vancomycin) affected visceral pain in adulthood, but did not impact cognitive or anxiety-related behaviors in male rats (O’Mahony et al., 2014).

Overall, the impact of antibiotics on brain development and behavior seems to be highly dependent upon factors such as the type and the dose used and the developmental time window when such exposure(s) occurred.

\section{Evidences From Human Data Impact of factors affecting the natural microbiota assembly on neurodevelopment}

The first evidences of the role of early microbiota composition or metabolic capacity and activity on neurodevelopment arise from studies linking factors that affect the natural assembly of the neonatal gut microbiota (mode of delivery, use of antibiotic, nutrition, etc.) and neurodevelopment. These studies should, however, be considered with caution, since these factors do not only affect gut colonization but also other pathways potentially affecting brain development. Nonetheless, these studies give a first idea of the link between microbiota and brain maturation in infancy.

\section{Mode of delivery}

C-section was associated with a delay in personal social skills and gross motor function at 9 months but not 3 years of age in a cohort of 11,000 infants (Al Khalaf et al., 2015). Likewise, a retrospective study with a lower number of infants $(n=104)$ but followed until 10 years of age indicated that C-section born infants have later attainment of developmental milestones compared to vaginally-born infants (Chojnacki et al., 2019). However, when studying brain health (attention deficit disorders and autism spectrum disorders), studies are very inconsistent and meta-analysis or large cohort studies could not conclude to any association (Curran et al., 2015, 2016).

\section{Use of antibiotics}

As antibiotics have long been considered safe, there is a paucity of studies evaluating the consequences of antibiotic treatment on brain development and subsequent function and behavior. A recent study on 342 children reported that antibiotic treatment in the first 6 months of life may trigger behavioral changes in 
children at 11 years of age, such as lower overall cognitive and verbal comprehension abilities, increased risk of problems with metacognition, executive function, impulsivity, attention-deficit hyperactivity, anxiety and emotion (Slykerman et al., 2019). This confirms a first study from the same research group in another cohort indicating that children that had received antibiotics in the first year of life had more behavioral difficulties and symptoms of depression at 11 years of age (Slykerman et al., 2017; Lavebratt et al., 2019). Moreover, it is noteworthy that drugs over than antibiotics can also have anti-microbial properties. The impact of early-life administration of these drugs on brain development warrants further investigations.

\section{Nutrition}

It has long been established that breast-feeding was associated with better neurodevelopment (Kramer et al., 2008; Quigley et al., 2012). Importantly, the effect is particularly noteworthy for preterm infants, who have an increased risk for behavioral problems and cognitive impairments later in life (Quigley et al., 2012). Recent data indicated that breast-feeding more than 1 month was associated with higher IQ compared to breast-feeding less than 1 month (Strøm et al., 2019). However, even though breast-feeding impacts gut microbiota composition, increasing for instance Bifidobacterium abundance, it is difficult to link these results to microbiota composition only as breast-milk provides specific nutrients known for their beneficial effects on brain development (LC-PUFAs, HMOs, etc.). However, Bifidobacterium species are responsible for the fermentation of HMOs to produce SCFAs (Marcobal et al., 2011). SCFAs improve the gut health by promoting intestinal barrier integrity maintenance, mucus production and intestinal hormone secretion (Gaudier et al., 2009; Peng et al., 2009; Tolhurst et al., 2012). In addition to exerting local effects in the colon, SCFAs play a pivotal role in microbiota-gutbrain crosstalk. Accumulating evidence suggests that SCFAs that cross the blood-brain barrier into the central nervous system have neuroactive properties. A multitude of animal studies have shown that SCFAs widespreadly may be involved in critical phases of neurodevelopmental and neurodegenerative disorders (Sharon et al., 2016; Dinan and Cryan, 2017; Fung et al., 2017; Kelly et al., 2017; Dalile et al., 2019). MFGM or some specific MFGM components such as sphingomyelin (phospholipids) have been reported to have positive association with the neurobehavioural development of infants born at term (Tanaka et al., 2013; Timby et al., 2014) and to change, though moderately, oral microbiome (lower level of Moraxella catarrhalis with MFGM supplementation compared to standard formula feeding) (Timby et al., 2017a). A recent systematic review on the effects of different nutritional interventions, including supplementation with amino acids and protein, lipids, probiotics, prebiotics, vitamins, and minerals, to reduce brain injury and/or improve neurodevelopmental outcomes in preterm infants (24 randomized controlled clinical trials included) concluded that positive effects of nutritional interventions have not been evidently demonstrated in these trials even though promising effects have been demonstrated in many pre-clinical studies (Hortensius et al., 2019). Concerning probiotics, Lactobacillus acidophilus and Bifidobacterium infantis (Chou et al., 2010), a combination of $B$. infantis, Streptococcus thermophilus, and Bifidobacterium lactis (Jacobs et al., 2017) or Lactobacillus Sporogenu (Sari et al., 2012), were administered the first week after birth until discharge and no significant effect of supplementation on neurodevelopmental outcome assessed between 2 and 5 years was found. It is noticeable that single, but not multiple, nutritional interventions were included in these studies. In addition, several relevant factors such as the type of infant nutrition (i.e., breast milk vs. formula or donor milk), the timing and the dose of the nutritional supplementation hampered the conclusions in preterm infant studies (Schneider and Garcia-Rodenas, 2017).

\section{Observational Prospective Studies}

\section{Behavior and temperament}

Few clinical studies evaluated the association between microbiota composition and later child behavior and temperament. A first exploratory investigation evaluated fecal microbiota composition (through $16 \mathrm{~S}$ sequencing) and concomitant temperament, rated by maternal questionnaires, in full-term healthy toddlers aged 18-27 months. Phylogenic diversity was associated with higher surgency/extraversion scores in both boys and girls (Christian et al., 2015). However, this study did not evaluate microbiota during infancy, which is the most rapid period of neurodevelopment. A second prospective study evaluated the link between microbiota composition (also through $16 \mathrm{~S}$ sequencing) at 2.5 months of age, i.e., during infancy, and temperament at 6 months in 300 full-term infants. Using a clustering strategy, they identified three distinct groups (discriminated by Bacteroidetes, Veillonella dispar and Bifidobacterium/Enterobacteriaceae, respectively). The Bacteroidetes cluster was associated with lower self-regulation capacity (a dimension that includes cuddliness, soothability, and orienting), compared to the Bifidobacterium/Enterobacteriaceae cluster. Moreover, negative emotionality and fear reactivity that may predict development of anxiety later in life, was associated with reduced diversity at the age of 6 months (Aatsinki et al., 2019). Finally, Loughman et al. (2020) used a different strategy to evaluate the link between infant behavior and microbiota: they looked for difference in microbiota composition at 1,6 , and 12 months of age (16S sequencing) of infants separated in behavior vs. non-behavior cases, based upon parent questionnaires completed at 2 years of age. While microbiota composition at 1 and 6 months of age was not different between the two populations, the presence of Prevotella at 12 months was significantly lower in the group of behavior cases (Loughman et al., 2020).

Overall, these studies point out the existence of correlations between microbial profiles and infant behavior but the identification of causal relationships warrants further investigations.

\section{Cognitive development}

Recently, two prospective observational studies linked earlylife microbiota composition to cognitive neurodevelopmental scores in full-term infants. Carlson et al. (2018) analyzed fecal 
microbiota composition through $16 \mathrm{~S}$ sequencing at 1 year of age in 89 full-term healthy infants and correlated them to the Mullen Scale of Early Learning (MSEL) scores and brain anatomy (MRI) at 1 and 2 years of age. Using a clustering strategy, they identified three groups of infants differing by their bacterial composition at 1 year of age [discriminated by Faecalibacterium, Bacteroidetes (and low Lachnospiraceae), and Ruminococcaceae, respectively]. These groups differed in term of MSEL cognitive score at 2, but not 1 , years of age. Indeed, infants in the Bacteroidetes cluster performed better, especially in the receptive and expressive language dimensions, than those in the Faecalibacterium and Ruminococcaceae clusters. Interestingly, predictor covariate of this better-performing group was breast-feeding and vaginal birth. Unrelatedly to this clustering approach, the authors also observed negative correlation between alpha-diversity at 1 year (number of observed species, Chaol index, Faith's phylogenetic diversity) and MSEL cognitive score at 2 years. This would suggest that, counterintuitively, a too great microbiota diversity at this period of life might be detrimental to neurodevelopment that would need confirmation in other studies. Association between microbiota composition or alpha-diversity and neuroimaging data indicated minimal effects of microbiota at 1 year on brain volume at 2 years of age.

A more recent study, enrolling 309 full-term healthy infants, evaluated the relationships between fecal microbiota composition, also estimated through $16 \mathrm{~S}$ sequencing, at 36 months of age and score of the Age and Stage Questionnaire (ASQ) at 3 years of age (Sordillo et al., 2019). The authors used a co-abundance factor approach, which allowed assigning four scores to each individual based on the co-abundance of the 25 most abundant bacterial taxa. They then mathematically correlated these microbiota scores to the ASQ scores. Interestingly, scores in communication and personal social skills were negatively associated with the microbiota factor comprising relative high abundance of Lachnospiraceae and Clostridiales and low abundance of Bacteroidetes, while fine motor skills scores were negatively correlated with the factor comprising relative high abundance of Bacteroidetes and low abundance of E. coli and Bifidobacterium, two early colonizers. A tendency for increased Shannon diversity index with lower personal and social skills was also noticed.

These two prospective observational studies both pointed early relative abundance of Bacteroidetes and Lachnospiraceae as phylum/family correlating to later cognitive scores: high Bacteroidetes and low Lachnospiraceae relative abundances correlated with better receptive and expressive language scores and communication and personal and social skills, but lower fine motor scores for Bacteroidetes abundance. Both studies also pointed out the importance of low diversity for adequate neurodevelopment. However, these recent exciting data need to be confirmed by other studies focusing on microbiota composition during the early weeks postnatally.

A paradigm shift in the concept of the origin of human neurodevelopmental and psychiatric disorders has emerged since the discovery of the link between gut microbiota and brain function and behavior (Mayer et al., 2014). This link between early life gut colonization and later neurodevelopmental outcomes is starting to arise, demonstrated by pre-clinical interventional studies but also rare clinical studies, focusing on normal-weight healthy term babies. However, the role of gut colonization in preterm neonates, who constitute a highrisk population in term of neurodevelopment has been poorly explored so far. Moreover, assessment of fecal microbiota composition at a single time does not fully capture the early life dynamical changes in the microbiota, which may also be important to neurocognitive outcomes. Bioinformatical tools and models aimed at linking microbiota composition and neurodevelopmental questionnaires or behavioral traits are also needed to step forward in the understanding of the microbiotabrain axis. Finally, although in the aforementioned clinical studies, the effects are often small at individual levels and do not demonstrate an increased risk of clinically significant behavioral or cognitive problems. At a population level, these effects could have a more substantial impact on the prevalence of abnormality, particularly for the more high-risk population in term of neurodevelopment.

\section{PROMISING \\ MICROBIOTA-MODULATION-BASED INTERVENTIONS FOR NEURODEVELOPMENTAL OUTCOMES}

Early body weight gain and macronutrient intake are positively related to brain volume and maturation and to neurodevelopmental outcomes in late infancy in very preterm infants (Coviello et al., 2018). As above reviewed several nutritional components of HM and infant formulas may influence gut microbiota which may have an impact on brain development and plasticity. Gut microbiota is capable to communicate with the central nervous system via the vagal nerve as well as microbiota-regulated intestinal production of cytokines, neurotransmitters, hormones and metabolites. Therefore, the development of microbiota modulation-based nutritional interventions may represent a novel strategy favoring gut colonization by beneficial bacteria and healthy microbiota with the aim of improving neurodevelopmental outcomes in preterm infants.

\section{Probiotics/Prebiotics}

It is well established that there is a relationship between the bacterial communities in HM and those of the recipient infant's feces (Lackey et al., 2019). Promoting breastfeeding is therefore an optimal way to ensure beneficial HM bacteria supply to the infant. However, when it is not wanted or possible, probiotic or prebiotic strategies may help to improve infant gut microbiota.

Prebiotics and probiotics are the most common ways to positively influence gut microbiota development in the early life. Prebiotics are defined as compounds that result in the 'selective stimulation of growth and activity of one or more microbial genus or species in the gut microbiota that confer health benefits to the host' (Roberfroid et al., 2010). The World Health Organization defines probiotics as 'live microorganisms which when administered in adequate amounts confer a health benefit on the host' (Food and Agriculture Organization of the 
United Nations and World Health Organization, 2001). Without probiotic and prebiotic supplementation, the gut microbiota of formula-fed infants is generally not dominated by the Bifidobacterium species (Bezirtzoglou et al., 2011; Oozeer et al., 2013; Musilova et al., 2014).

Among Lactobacillus and Bifidobacterium species isolated from human milk, many of them (Lactobacillus salivarius, Lactobacillus gasseri, Lactobacillus reuteri, Lactobacillus plantarum, Lactobacillus rhamnosus, Lactobacillus fermentum, Bifidobacterium breve, Bifidobacterium longum, and Bifidobacterium bifidum) were included among the potentially probiotic ones and enjoyed the GRAS (Generally Recognized As Safe; FDA, United States) and the QPS (Qualified Presumption of Safety; EFSA, EU) status (Koutsoumanis et al., 2020).

\section{Probiotic Therapy During Pregnancy or for Infant Nutrition}

The first bacteria that colonize the infant gut at birth may originate from the maternal fecal, vaginal and breast milk microbiota, suggesting that the development of strategies to modulate maternal microbiota during pregnancy may be beneficial for neonates. In this context, L. rhamnosus, supplied to women during and after pregnancy, was correlated with an increase in the abundance of Bifidobacterium and Lactobacillus in the infant microbiota gut (Gueimonde et al., 2006; Lahtinen et al., 2009). In preterm infants, Saccharomyces boulardii can be used to regulate the growth of Candida. The enteral administration of bacterial and fungal probiotics, such as L. reuteri, Lactobacillus casei, L. rhamnosus, L. acidophilus, S. thermophilus, Bifidobacterium longum, Bifidobacterium bifidum, Bifidobacterium lactis and S. boulardii has also been used to reduce invasive candidiasis (Kaufman et al., 2006; Manzoni et al., 2015). In very preterm infants oral administration of either L. rhamnosus ATCC 53103 or L. reuteri ATCC 55730 was effective in the prevention of gastrointestinal colonization by Candida and may help to prevent suboptimal neurological outcomes (Romeo et al., 2011).

Several evidences from pre-clinical models clearly demonstrated the early interaction between microbiota and the brain and how probiotic supplementation may favor brain restoration, even though it was not clearly evidenced in human studies. The term 'psychobiotics to describe an emerging class of probiotics of relevance to psychiatry' has even been proposed (Dinan et al., 2013). Psychobiotics are probiotic strains that have shown behavioral effects in preclinical models, are able to promote the production of neuroactive substances such as gamma-aminobutyric acid and serotonin involved in the gut-brain axis, and have a capacity to decrease proinflammatory cytokines and reduce the hypothalamic-pituitary-adrenal (HPA) activity. Further research is warranted to expand the investigation of the benefits of psychobiotics within human preterm population as having a significant impact on cognition (Lv et al., 2021).

\section{Microbiota Regulation Through Prebiotics}

In pregnant women, galacto-oligosaccharides (GOS)/fructooligosaccharides (FOS) supplementation significantly increased fecal bifidobacterial levels, with potential benefits for the transmission of beneficial bacteria to their infant during the birth process (Firmansyah et al., 2016; Lv et al., 2021). The main prebiotics used in infant formula are short-chain GOS, long-chain FOS and polydextrose (PDX). Addition of GOS, a GOS/FOS mixture or PDX to infant formula has been shown to be effective in increasing lactobacilli and on bifidobacteria abundance (Knol et al., 2005; Rinne et al., 2005; Ben et al., 2008; Scalabrin et al., 2012; Sierra et al., 2015; Vandenplas et al., 2015). Finally, preterm infants given FOS-supplemented formula displayed an increased count of bifidobacteria and a corresponding significant reduction of $E$. coli and enterococci in fecal samples (Kapiki et al., 2007).

The use of prebiotics in infant formula is already a common practice to reduce digestive discomfort in term infants, even though scientific-based evidences are still too weak to state with certainty. In preterms, effects of GOS/FOS/pectin-derived acidic oligosaccharides on neurodevelopmental outcomes were measured by Bayley Scales of Infant and Toddler Development at 2 years (van den Berg et al., 2016). No significant improvement of neurodevelopmental outcomes was observed. However, lower bifidobacteria counts and higher serum cytokine levels during the neonatal period were associated with lower neurodevelopmental outcomes at 24 months of age, suggesting that an opportunity to influence neurodevelopment of these preterm infants via cytokine and microbiome modulation may exist (van den Berg et al., 2016). Future research is needed to provide more insights into the mechanisms of prebiotics and of combination of probiotics and prebiotics called 'synbiotics', and their further use in preterm infants.

\section{Maternal Nutrition}

As seen above, maternal nutrition is able to modulate, yet modestly, HM composition. One exciting strategy would be to try to modulate $\mathrm{HM}$ components known to drive infant gut microbiota, such as HM microbiota or HMOs or specific lipids content, through maternal nutrition but this remains very hypothetical to date. Indeed, the effects of maternal nutrition on infant microbiota have been poorly explored and deserve more studies. A recent study suggested that maternal diet does influence the infant gut microbiota and that these effects differ by delivery mode (Lundgren et al., 2018). Some effects of maternal diet were more apparent in exclusively breastfed infants, suggesting a role of HM in the effects observed on gut microbiota (Lundgren et al., 2018). Increased fruit intake by mothers was associated with increased belonging to the high Streptococcus/Clostridium group among infants born vaginally and maternal dairy intake was associated with increased belonging to the high Clostridium cluster in infant born by cesarean section (Lundgren et al., 2018). Some consistent associations between maternal DHA and EPA intake (through fish and seafood consumption) and infant gut microbiota profiles were also observed: maternal fish and seafood consumption was positively related to Streptococcus in the infant gut, and associated to a decrease in Clostridium neonatale in infants born by cesarean section (Lundgren et al., 2018). More indirectly, maternal gestational weight gain was associated with the infant fecal microbiota profiles (Robinson et al., 2017). Infant whose 
mothers had higher gestational gain weight were less likely to have a Bacteroides-dominant profile, had a lower bacterial community richness and Shannon diversity index (Robinson et al., 2017).

\section{CONCLUSION}

Initial colonization and microbiota development in preterm infants differ from that in term infants. Increasing evidences suggest that intestinal dysbiosis in preterm infants predisposes the neonate to adverse neurological outcomes later in life. The increase in brain growth occurring in parallel with the infant microbiota complexification during the early period of life is a period of opportunity in which nutritional interventions (e.g., probiotics, psychobiotics, prebiotics, synbiotics, and maternal nutrition) may have their maximal effects on the gut-brain communication and provide benefits to enhance maturation and shape brain development. Consequently, it is essential to develop

\section{REFERENCES}

Aatsinki, A. K., Lahti, L., Uusitupa, H. M., Munukka, E., Keskitalo, A., Nolvi, S., et al. (2019). Gut microbiota composition is associated with temperament traits in infants. Brain Behav. Immun. 80, 849-858. doi: 10.1016/j.bbi.2019.05.035

Agostoni, C., Buonocore, G., Carnielli, V.P., De Curtis, M., Darmaun, D., Decsi, T., et al. (2010). Enteral nutrient supply for preterm infants: commentary from the european society of paediatric gastroenterology, Hepatology and Nutrition Committee on nutrition. J. Pediatr. Gastroenterol. Nutr. 50, 85-91. doi: 10.1097/ MPG.0b013e3181adaee0

Al Khalaf, S.Y., O’Neill, S.M., O’Keeffe, L.M., Henriksen, T.B., Kenny, L.C., Cryan, J.F., et al. (2015). The impact of obstetric mode of delivery on childhood behavior. Soc. Psychiatry Psychiatr. Epidemiol. 50, 1557-1567. doi: 10.1007/ s00127-015-1055-9

Alou, M.T., Lagier, J.-C., and Raoult, D. (2016). Diet influence on the gut microbiota and dysbiosis related to nutritional disorders. Hum. Microb. J. 1, $3-11$.

Alyahya, W., Simpson, J., Garcia, A. L., Mactier, H., and Edwards, C. A. (2020). Early versus delayed fortification of human milk in preterm infants: a systematic review. Neonatology 117, 24-32. doi: 10.1159/000501279

Arentsen, T., Qian, Y., Gkotzis, S., Femenia, T., Wang, T., Udekwu, K., et al. (2017). The bacterial peptidoglycan-sensing molecule Pglyrp 2 modulates brain development and behavior. Mol. Psychiatry 22, 257-266. doi: 10.1038/mp.2016. 182

Arentsen, T., Raith, H., Qian, Y., Forssberg, H., and Diaz Heijtz, R. (2015). Host microbiota modulates development of social preference in mice. Microb. Ecol. Health Dis. 26:29719. doi: 10.3402/mehd.v26.29719

Arslanoglu, S., Boquien, C. Y., King, C., Lamireau, D., Tonetto, P., Barnett, D., et al. (2019). Fortification of human milk for preterm infants: update and recommendations of the European Milk Bank Association (EMBA) working group on human milk fortification. Front. Pediatr. 7:76. doi: 10.3389/fped.2019. 00076

Asztalos, E.V., Barrington, K., Lodha, A., Tarnow-Mordi, W., and Martin, A. (2020). Lactoferrin infant feeding trial_Canada (LIFT_Canada): protocol for a randomized trial of adding lactoferrin to feeds of very-low-birth-weight preterm infants. BMC Pediatr. 20:40. doi: 10.1186/s12887-020-1938-0

Atiya Ali, M., Strandvik, B., Sabel, K.G., Palme Kilander, C., Strömberg, R., and Yngve, A. (2014). Polyamine levels in breast milk are associated with mothers' dietary intake and are higher in preterm than full-term human milk and formulas. J. Hum. Nutr. Diet 27, 459-467. doi: 10.1111/jhn.12156

Austin, S., De Castro, C. A., Sprenger, N., Binia, A., Affolter, M., Garcia-Rodenas, C. L., et al. (2019). Human milk Oligosaccharides in the milk of mothers delivering term versus preterm infants. Nutrients 11:1282. novel microbiota modulation-based nutritional interventions for infants and young children at high-risk for neurodevelopmental disorders. With the key characters of immaturity of preterm infants, we propose the possibility to manipulate the microbiota in early life as a preventive strategy to neurodevelopmental disorders. Identified critical windows may concern maternal nutrition through pregnancy and lactation and the infant nutrition during the early postnatal period (0-6 weeks of life). Translational research in this field is limited and further investigation of the efficacy of nutritional strategies in early life is warranted.

\section{AUTHOR CONTRIBUTIONS}

SB-B, GB, SB, and IH-L: conceptualization and original draft preparation. SB-B, AmB, GB, J-PG, MY, AlB, SB, and IH-L: writing-review and editing. All authors read and agreed to the published version of the manuscript.

Autran, C.A., Kellman, B.P., Kim, J.H., Asztalos, E., Blood, A.B., Spence, E.C.H., et al. (2018). Human milk oligosaccharide composition predicts risk of necrotising Enterocolitis in preterm infants. Gut 67:1064-1070. doi: 10.1136/ gutjnl-2016-312819

Azad, M. B., Robertson, B., Atakora, F., Becker, A. B., Subbarao, P., Moraes, T. J., et al. (2018). Human milk oligosaccharide concentrations are associated with multiple fixed and modifiable maternal characteristics, environmental factors, and feeding practices. J. Nutr. 148, 1733-1742. doi: 10.1093/jn/ nxy 175

Azad, M.B., Konya, T., Maughan, H., Guttman, D.S., Field, C.J., Chari, R.S., et al. (2013). Gut microbiota of healthy Canadian infants: profiles by mode of delivery and infant diet at 4 months. CMAJ 185, 385-394. doi: 10.1503/cmaj.121189

Babakobi, M.D., Reshef, L., Gihaz, S., Belgorodsky, B., Fishman, A., Bujanover, Y., et al. (2020). Effect of maternal diet and milk lipid composition on the infant gut and maternal milk microbiomes. Nutrients 12:2539. doi: 10.3390/nu12092539

Bäckhed, F., Roswall, J., Peng, Y., Feng, Q., Jia, H., Kovatcheva-Datchary, P., et al. (2015). Dynamics and stabilization of the human gut microbiome during the first year of life. Cell Host. Microbe 17, 690-703. doi: 10.1016/j.chom.2015.04. 004

Ballard, O., and Morrow, A.L. (2013). Human milk composition: nutrients and bioactive factors. Pediatr. Clin. North Am. 60, 49-74. doi: 10.1016/j.pcl.2012. 10.002

Barrera, C., Valenzuela, R., Chamorro, R., Bascuñán, K., Sandoval, J., Sabag, N., et al. (2018). The impact of maternal diet during pregnancy and lactation on the fatty acid composition of erythrocytes and breast milk of chilean women. Nutrients 10:839. doi: 10.3390/nu10070839

Bauer, J., and Gerss, J. (2011). Longitudinal analysis of macronutrients and minerals in human milk produced by mothers of preterm infants. Clin. Nutr. 30, 215-220. doi: 10.1016/j.clnu.2010.08.003

Ben, X.M., Li, J., Feng, Z.T., Shi, S.Y., Lu, Y.D., Chen, R., et al. (2008). Low level of galacto-oligosaccharide in infant formula stimulates growth of intestinal Bifidobacteria and Lactobacilli. World J. Gastroenterol. 14, 6564-6568. doi: 10. 3748/wjg.14.6564

Berenhauser, A.C., Pinheiro do Prado, A.C., da Silva, R.C., Gioielli, L.A., and Block, J.M. (2012). Fatty acid composition in preterm and term breast milk. Int. J. Food Sci. Nutr. 63, 318-325. doi: 10.3109/09637486.2011.627843

Berger, P. K., Fields, D. A., Demerath, E. W., Fujiwara, H., and Goran, M. I. (2018). High-fructose corn-syrup-sweetened beverage intake increases 5-hour breast milk fructose concentrations in lactating women. Nutrients 10:669. doi: $10.3390 /$ nu 10060669

Bering, S. B. (2018). Human milk oligosaccharides to prevent gut dysfunction and necrotizing Enterocolitis in preterm neonates. Nutrients 10:1461. doi: 10.3390/ nu10101461 
Beverly, R. L., Huston, R. K., Markell, A. M., McCulley, E. A., Martin, R. L., and Dallas, D. C. (2019). Milk peptides survive in vivo gastrointestinal digestion and are excreted in the stool of infants. J. Nutr. 150, 712-721. doi: 10.1093/jn/ nxz326

Bezirtzoglou, E., Tsiotsias, A., and Welling, G. W. (2011). Microbiota profile in feces of breast- and formula-fed newborns by using fluorescence in situ hybridization (FISH). Anaerobe 17, 478-482. doi: 10.1016/j.anaerobe.2011.03. 009

Bitman, J., Wood, D.L., Mehta, N.R., Hamosh, P., and Hamosh, M. (1984). Comparison of the phospholipid composition of breast milk from mothers of term and preterm infants during lactation. Am. J. Clin. Nutr. 40:1103-1119. doi: $10.1093 / \mathrm{ajcn} / 40.5 .1103$

Boix-Amorós, A., Martinez-Costa, C., Querol, A., Collado, M. C., and Mira, A. (2017). Multiple Approaches Detect the Presence of Fungi in Human Breastmilk Samples from Healthy Mothers. Sci. Rep. 7:13016. doi: 10.1038/ s41598-017-13270-x

Boix-Amorós, A., Puente-Sánchez, F., du Toit, E., Linderborg, K. M., Zhang, Y., Yang, B., et al. (2019). Mycobiome profiles in breast milk from healthy women depend on mode of delivery, geographic location, and interaction with bacteria. Appl. Environ. Microbiol. 85, e02994-18. doi: 10.1128/aem.02994-18

Borre, Y. E., Moloney, R. D., Clarke, G., Dinan, T. G., and Cryan, J. F. (2014a). The impact of microbiota on brain and behavior: mechanisms \& therapeutic potential. Adv. Exp. Med. Biol. 817, 373-403. doi: 10.1007/978-1-4939-0897-4_ 17

Borre, Y.E., O'Keeffe, G.W., Clarke, G., Stanton, C., Dinan, T.G., and Cryan, J.F. (2014b). Microbiota and neurodevelopmental windows: implications for brain disorders. Trends Mol. Med. 20, 509-518. doi: 10.1016/j.molmed.2014.05.002

Boudry, C., Le Huërou-Luron, I., Michel, C. (2016). "Dietary protein and colonic microbiota: molecular aspects," in The Molecular Nutrition of Amino Acids and Proteins, ed. D. Dardevet. (Boston: Academic Press), 341-353.

Boudry, G., Charton, E., Le Huerou-Luron, I., Ferret-Bernard, S., Le Gall, S., Even, S., et al. (2021). The relationship between breast milk components and the infant gut microbiota. Front. Nutr. 8:629740. doi: 10.3389/fnut.2021.629740

Boudry, G., Jamin, A., Chatelais, L., Gras-Le Guen, C., Michel, C., and Le HuerouLuron, I. (2013). Dietary protein excess during neonatal life alters colonic microbiota and mucosal response to inflammatory mediators later in life in female pigs. J. Nutr. 143, 1225-1232. doi: 10.3945/jn.113.175828

Bourlieu, C., Bouzerzour, K., Ferret-Bernard, S., Bourgot, C. L., Chever, S., Ménard, O., et al. (2015). Infant formula interface and fat source impact on neonatal digestion and gut microbiota. Eur. J. Lipid Sci. Technol. 117, 1500-1512. doi: 10.1002/ejlt.201500025

Braniste, V., Al-Asmakh, M., Kowal, C., Anuar, F., Abbaspour, A., Tóth, M., et al. (2014). The gut microbiota influences blood-brain barrier permeability in mice. Sci. Transl. Med. 6:263ra158. doi: 10.1126/scitranslmed.3009759

Briliute, J., Urbanowicz, P. A., Luis, A. S., Basle, A., Paterson, N., Rebello, O., et al. (2019). Complex N-glycan breakdown by gut Bacteroides involves an extensive enzymatic apparatus encoded by multiple co-regulated genetic loci. Nat. Microbiol. 4, 1571-1581. doi: 10.1038/s41564-019-0466-x

Brooks, B., Firek, B.A., Miller, C.S., Sharon, I., Thomas, B.C., Baker, R., et al. (2014). Microbes in the neonatal intensive care unit resemble those found in the gut of premature infants. Microbiome 2:1. doi: 10.1186/2049-2618-2-1

Brooks, B., Olm, M.R., Firek, B.A., Baker, R., Geller-McGrath, D., Reimer, S.R., et al. (2018). The developing premature infant gut microbiome is a major factor shaping the microbiome of neonatal intensive care unit rooms. Microbiome 6:12. doi: 10.1186/s40168-018-0493-5

Bulut, O., Coban, A., and Ince, Z. (2019). Macronutrient analysis of preterm human milk using mid-infrared spectrophotometry. J. Perinat. Med. 47, 785-791. doi: 10.1515/jpm-2019-0105

Burianova, I., Bronsky, J., Pavlikova, M., Janota, J., and Maly, J. (2019). Maternal body mass index, parity and smoking are associated with human milk macronutrient content after preterm delivery. Early Hum. Dev. 137:04832. doi: 10.1016/j.earlhumdev.2019.104832

Burokas, A., Moloney, R. D., Dinan, T. G., and Cryan, J. F. (2015). Microbiota regulation of the Mammalian gut-brain axis. Adv. Appl. Microbiol. 91, 1-62. doi: 10.1016/bs.aambs.2015.02.001

Butel, M. J., Suau, A., Campeotto, F., Magne, F., Aires, J., Ferraris, L., et al. (2007). Conditions of bifidobacterial colonization in preterm infants: a prospective analysis. J. Pediatr. Gastroenterol. Nutr. 44, 577-582. doi: 10.1097/MPG. 0b013e3180406b20

Bzikowska-Jura, A., Czerwonogrodzka-Senczyna, A., Jasińska-Melon, E., Mojska, H., Olêdzka, G., Wesołowska, A., et al. (2019). The concentration of Omega3 fatty acids in human milk is related to their habitual but not current intake. Nutrients 11:1585. doi: 10.3390/nu11071585

Carlson, A. L., Xia, K., Azcarate-Peril, M. A., Goldman, B. D., Ahn, M., Styner, M. A., et al. (2018). Infant Gut Microbiome Associated With Cognitive Development. Biol. Psychiatry 83, 148-159. doi: 10.1016/j.biopsych.2017.06. 021

Carr, L.E., Virmani, M.D., Rosa, F., Munblit, D., Matazel, K.S., Elolimy, A.A., et al. (2021). Role of human milk bioactives on infants' gut and immune health. Front. Immunol. 12:604080. doi: 10.3389/fimmu.2021.604080

Castellote, C., Casillas, R., Ramirez-Santana, C., Perez-Cano, F.J., Castell, M., Moretones, M.G., et al. (2011). Premature delivery influences the immunological composition of colostrum and transitional and mature human milk. J. Nutr. 141, 1181-1187. doi: 10.3945/jn.110.133652

Catanzaro, J. R., Strauss, J. D., Bielecka, A., Porto, A. F., Lobo, F. M., Urban, A., et al. (2019). IgA-deficient humans exhibit gut microbiota dysbiosis despite secretion of compensatory IgM. Sci. Rep. 9:13574. doi: 10.1038/s41598-01949923-2

Cenit, M. C., Sanz, Y., and Codoner-Franch, P. (2017). Influence of gut microbiota on neuropsychiatric disorders. World J. Gastroenterol. 23, 5486-5498. doi: 10. 3748/wjg.v23.i30.5486

Chan, S. H., Johnson, M. J., Leaf, A. A., and Vollmer, B. (2016). Nutrition and neurodevelopmental outcomes in preterm infants: a systematic review. Acta Paediatr. 105, 587-599. doi: 10.1111/apa.13344

Chatelais, L., Jamin, A., Gras-Le Guen, C., Lalles, J. P., Le Huerou-Luron, I., and Boudry, G. (2011). The level of protein in milk formula modifies ileal sensitivity to LPS later in life in a piglet model. PLoS One 6:e19594. doi: 10.1371/journal. pone.0019594

Cheong, J. L., Thompson, D. K., Spittle, A. J., Potter, C. R., Walsh, J. M., Burnett, A. C., et al. (2016). Brain volumes at term-equivalent age are associated with 2Year neurodevelopment in moderate and late preterm children. J. Pediatr. 174, 91-97. doi: 10.1016/j.jpeds.2016.04.002

Chojnacki, M. R., Holscher, H. D., Balbinot, A. R., Raine, L. B., Biggan, J. R., Walk, A. M., et al. (2019). Relations between mode of birth delivery and timing of developmental milestones and adiposity in preadolescence: A retrospective study. Early Hum. Dev. 129, 52-59. doi: 10.1016/j.earlhumdev.2018.12.021

Chou, I. C., Kuo, H. T., Chang, J. S., Wu, S. F., Chiu, H. Y., Su, B. H., et al. (2010). Lack of effects of oral probiotics on growth and neurodevelopmental outcomes in preterm very low birth weight infants. J. Pediatr. 156, 393-396. doi: 10.1016/j.jpeds.2009.09.051

Christian, L.M., Galley, J.D., Hade, E.M., Schoppe-Sullivan, S., Kamp Dush, C., and Bailey, M.T. (2015). Gut microbiome composition is associated with temperament during early childhood. Brain Behav. Immun. 45, 118-127. doi: 10.1016/j.bbi.2014.10.018

Claud, E.C., Keegan, K.P., Brulc, J.M., Lu, L., Bartels, D., Glass, E., et al. (2013). Bacterial community structure and functional contributions to emergence of health or necrotizing enterocolitis in preterm infants. Microbiome 1:20. doi: 10.1186/2049-2618-1-20

Constable, R.T., Ment, L.R., Vohr, B.R., Kesler, S.R., Fulbright, R.K., Lacadie, C., et al. (2008). Prematurely born children demonstrate white matter microstructural differences at 12 years of age, relative to term control subjects: an investigation of group and gender effects. Pediatrics 121, 306-316. doi: 10.1542/peds.2007-0414

Coppa, G.V., Pierani, P., Zampini, L., Gabrielli, O., Carlucci, A., Catassi, C., et al. (1997). Lactose, oligosaccharide and monosaccharide content of milk from mothers delivering preterm newborns over the first month of lactation. Minerva Pediatr. 49, 471-475.

Courchesne, E., Karns, C.M., Davis, H.R., Ziccardi, R., Carper, R.A., Tigue, Z.D., et al. (2001). Unusual brain growth patterns in early life in patients with autistic disorder: an MRI study. Neurology 57, 245-254. doi: 10.1212/wnl.57.2.245

Coviello, C., Keunen, K., Kersbergen, K. J., Groenendaal, F., Leemans, A., Peels, B., et al. (2018). Effects of early nutrition and growth on brain volumes, white matter microstructure, and neurodevelopmental outcome in preterm newborns. Pediatr. Res. 83, 102-110. doi: 10.1038/pr.2017.227 
Cryan, J.F., and Dinan, T.G. (2015). More than a gut feeling: the microbiota regulates neurodevelopment and behavior. Neuropsychopharmacology 40(1), 241-242. doi: 10.1038/npp.2014.224

Curran, E. A., Cryan, J. F., Kenny, L. C., Dinan, T. G., Kearney, P. M., and Khashan, A. S. (2016). Obstetrical mode of delivery and childhood behavior and psychological development in a british cohort. J. Autism Dev. Disord. 46, 603-614. doi: 10.1007/s10803-015-2616-1

Curran, E.A., Dalman, C., Kearney, P.M., Kenny, L.C., Cryan, J.F., Dinan, T.G., et al. (2015). Association between obstetric mode of delivery and autism spectrum disorder: a population-based sibling design study. JAMA Psychiatry 72(9), 935-942. doi: 10.1001/jamapsychiatry.2015.0846

Dahl, C., Stigum, H., Valeur, J., Iszatt, N., Lenters, V., Peddada, S., et al. (2018). Preterm infants have distinct microbiomes not explained by mode of delivery, breastfeeding duration or antibiotic exposure. Int. J. Epidemiol. 47, 1658-1669. doi: 10.1093/ije/dyy064

Dalile, B., Van Oudenhove, L., Vervliet, B., and Verbeke, K. (2019). The role of short-chain fatty acids in microbiota-gut-brain communication. Nat. Rev. Gastroenterol. Hepatol. 16, 461-478. doi: 10.1038/s41575-019-0157-3

De Leoz, M. L. A., Gaerlan, S. C., Strum, J. S., Dimapasoc, L. M., Mirmiran, M., Tancredi, D. J., et al. (2012). Lacto-N-Tetraose, fucosylation, and secretor status are highly variable in human milk Oligosaccharides from women delivering preterm. J. Proteome Res. 11, 4662-4672. doi: 10.1021/pr3004979

De Leoz, M. L., Kalanetra, K. M., Bokulich, N. A., Strum, J. S., Underwood, M. A., German, J. B., et al. (2015). Human milk glycomics and gut microbial genomics in infant feces show a correlation between human milk oligosaccharides and gut microbiota: a proof-of-concept study. J. Proteome Res. 14, 491-502. doi: $10.1021 /$ pr500759e

de Oliveira, S.C., Bourlieu, C., Ménard, O., Bellanger, A., Henry, G., Rousseau, F., et al. (2016). Impact of pasteurization of human milk on preterm newborn in vitro digestion: Gastrointestinal disintegration, lipolysis and proteolysis. Food Chem. 211, 171-179. doi: 10.1016/j.foodchem.2016.05.028

Dean, J. M., Bennet, L., Back, S. A., McClendon, E., Riddle, A., and Gunn, A. J. (2014). What brakes the preterm brain? An arresting story. Pediatr. Res. 75, 227-233. doi: 10.1038/pr.2013.189

Delplanque, B., Gibson, R., Koletzko, B., Lapillonne, A., and Strandvik, B. (2015). Lipid quality in infant nutrition: current knowledge and future opportunities. J. Pediatr. Gastroenterol. Nutr. 61, 8-17. doi: 10.1097/MPG.0000000000000818

Desbonnet, L., Clarke, G., Shanahan, F., Dinan, T.G., and Cryan, J.F. (2014). Microbiota is essential for social development in the mouse. Mol. Psychiatry 19, 146-148. doi: 10.1038/mp.2013.65

Diaz Heijtz, R., Wang, S., Anuar, F., Qian, Y., Bjorkholm, B., Samuelsson, A., et al. (2011). Normal gut microbiota modulates brain development and behavior. Proc. Natl. Acad. Sci. U S A 108, 3047-3052. doi: 10.1073/pnas.1010529108

Dinan, T. G., Stanton, C., and Cryan, J. F. (2013). Psychobiotics: a novel class of psychotropic. Biol. Psychiatry 74, 720-726. doi: 10.1016/j.biopsych.2013.05.001

Dinan, T.G., and Cryan, J.F. (2017). Gut instincts: microbiota as a key regulator of brain development, ageing and neurodegeneration. J. Physiol. 595, 489-503. doi: $10.1113 /$ jp273106

Dinan, T.G., Borre, Y.E., and Cryan, J.F. (2014). Genomics of schizophrenia: time to consider the gut microbiome? Mol. Psychiatry 19, 1252-1257. doi: 10.1038/ mp.2014.93

Dollive, S., Chen, Y. Y., Grunberg, S., Bittinger, K., Hoffmann, C., Vandivier, L., et al. (2013). Fungi of the murine gut: episodic variation and proliferation during antibiotic treatment. PLoS One 8:e71806. doi: 10.1371/journal.pone. 0071806

Dominguez-Bello, M.G., Costello, E.K., Contreras, M., Magris, M., Hidalgo, G., Fierer, N., et al. (2010). Delivery mode shapes the acquisition and structure of the initial microbiota across multiple body habitats in newborns. Proc. Natl. Acad. Sci. U S A 107, 11971-11975. doi: 10.1073/pnas.1002601107

Donaldson, G. P., Ladinsky, M. S., Yu, K. B., Sanders, J. G., Yoo, B. B., Chou, W. C., et al. (2018). Gut microbiota utilize immunoglobulin A for mucosal colonization. Science 360, 795-800. doi: 10.1126/science.aaq0926

Drell, T., Lillsaar, T., Tummeleht, L., Simm, J., Aaspollu, A., Vain, E., et al. (2013). Characterization of the vaginal micro- and mycobiome in asymptomatic reproductive-age Estonian women. PLoS One 8:e54379. doi: 10.1371/journal. pone.0054379

Dumitru, R., Hornby, J. M., and Nickerson, K. W. (2004). Defined anaerobic growth medium for studying Candida albicans basic biology and resistance to eight antifungal drugs. Antimicrob. Agents Chemother. 48, 2350-2354. doi: 10.1128/aac.48.7.2350-2354.2004

Ehrenkranz, R. A., Dusick, A. M., Vohr, B. R., Wright, L. L., Wrage, L. A., and Poole, W. K. (2006). Growth in the neonatal intensive care unit influences neurodevelopmental and growth outcomes of extremely low birth weight infants. Pediatrics 117, 1253-1261. doi: 10.1542/peds.2005-1368

Erny, D., Hrabì de Angelis, A. L., Jaitin, D., Wieghofer, P., Staszewski, O., David, E., et al. (2015). Host microbiota constantly control maturation and function of microglia in the CNS. Nat. Neurosci. 18, 965-977. doi: 10.1038/nn.4030

European Society of Paediatric Gastroenterology and Nutrition Committee on Nutrition of the Preterm Infant. (1987). Nutrition and feeding of preterm infants. Acta Paediatr. Scand Suppl. 336, 1-14.

Favier, C.F., Vaughan, E.E., De Vos, W.M., and Akkermans, A.D. (2002). Molecular monitoring of succession of bacterial communities in human neonates. Appl. Environ. Microbiol. 68, 219-226. doi: 10.1128/aem.68.1.219-226.2002

Finegold, S. M., Dowd, S. E., Gontcharova, V., Liu, C., Henley, K. E., Wolcott, R. D., et al. (2010). Pyrosequencing study of fecal microflora of autistic and control children. Anaerobe 16, 444-453. doi: 10.1016/j.anaerobe.2010.06.008

Firmansyah, A., Chongviriyaphan, N., Dillon, D. H., Khan, N. C., Morita, T., Tontisirin, K., et al. (2016). Fructans in the first 1000 days of life and beyond, and for pregnancy. Asia Pac. J. Clin. Nutr. 25, 652-675. doi: 10.6133/apjen. 092016.02

Fischer Fumeaux, C. J., Garcia-Rodenas, C. L., De Castro, C. A., CourtetCompondu, M. C., Thakkar, S. K., Beauport, L., et al. (2019). Longitudinal analysis of macronutrient composition in preterm and term human milk: A prospective cohort study. Nutrients 11:1525. doi: 10.3390/nu11071525

Fitzstevens, J.L., Smith, K.C., Hagadorn, J.I., Caimano, M.J., Matson, A.P., and Brownell, E.A. (2017). Systematic review of the human milk microbiota. Nutr. Clin. Pract. 32, 354-364. doi: 10.1177/0884533616670150

Food and Agriculture Organization of the United Nations and World Health Organization (2001). Evaluation of health and nutritional properties of powder milk and live lactic acid bacteria. Food and Agriculture Organization and World Health Organization Expert Consultation: Córdoba, Argentina.

Fouhy, F., Guinane, C. M., Hussey, S., Wall, R., Ryan, C. A., Dempsey, E. M., et al. (2012). High-throughput sequencing reveals the incomplete, short-term recovery of infant gut microbiota following parenteral antibiotic treatment with ampicillin and gentamicin. Antimicrob. Agents Chemother. 56, 5811-5820. doi: 10.1128/aac.00789-12

Fragkou, P. C., Karaviti, D., Zemlin, M., and Skevaki, C. (2021). Impact of early life nutrition on children's immune system and noncommunicable diseases through its effects on the bacterial microbiome, virome and mycobiome. Front. Immunol. 12:644269. doi: 10.3389/fimmu.2021.644269

Fung, T.C., Olson, C.A., and Hsiao, E.Y. (2017). Interactions between the microbiota, immune and nervous systems in health and disease. Nat. Neurosci. 20, 145-155. doi: 10.1038/nn.4476

Gabrielli, O., Zampini, L., Galeazzi, T., Padella, L., Santoro, L., Peila, C., et al. (2011). Preterm milk oligosaccharides during the first month of lactation. Pediatrics 128, e1520-e1531. doi: 10.1542/peds.2011-1206

Gasparrini, A.J., Crofts, T.S., Gibson, M.K., Tarr, P.I., Warner, B.B., and Dantas, G. (2016). Antibiotic perturbation of the preterm infant gut microbiome and resistome. Gut. Microbes 7, 443-449. doi: 10.1080/19490976.2016.1218584

Gaudier, E., Rival, M., Buisine, M.P., Robineau, I., and Hoebler, C. (2009). Butyrate enemas upregulate Muc genes expression but decrease adherent mucus thickness in mice colon. Physiol. Res. 58, 111-119.

Gibson, M. K., Wang, B., Ahmadi, S., Burnham, C. A., Tarr, P. I., Warner, B. B., et al. (2016). Developmental dynamics of the preterm infant gut microbiota and antibiotic resistome. Nat. Microbiol. 1:16024. doi: 10.1038/nmicrobiol.2016.24

Gidrewicz, D.A., and Fenton, T.R. (2014). A systematic review and meta-analysis of the nutrient content of preterm and term breast milk. BMC Pediatr. 14:216. doi: 10.1186/1471-2431-14-216

Giedd, J. N. (2004). Structural magnetic resonance imaging of the adolescent brain. Ann. N Y. Acad. Sci. 1021, 77-85. doi: 10.1196/annals.1308.009

Gomez-Gallego, C., Garcia-Mantrana, I., Salminen, S., and Collado, M.C. (2016). The human milk microbiome and factors influencing its composition and activity. Semin. Fetal. Neonatal. Med. 21, 400-405. doi: 10.1016/j.siny.2016.05. 003

Gopalakrishna, K.P., Macadangdang, B.R., Rogers, M.B., Tometich, J.T., Firek, B.A., Baker, R., et al. (2019). Maternal IgA protects against the development 
of necrotizing enterocolitis in preterm infants. Nat. Med. 25, 1110-1115. doi: 10.1038/s41591-019-0480-9

Granot, E., Ishay-Gigi, K., Malaach, L., and Flidel-Rimon, O. (2016). Is there a difference in breast milk fatty acid composition of mothers of preterm and term infants? J. Matern Fetal. Neonatal. Med. 29, 832-835. doi: 10.3109/14767058. 2015.1020785

Gregory, K.E., Samuel, B.S., Houghteling, P., Shan, G., Ausubel, F.M., Sadreyev, R.I., et al. (2016). Influence of maternal breast milk ingestion on acquisition of the intestinal microbiome in preterm infants. Microbiome 4:8. doi: 10.1186/ s40168-016-0214-x

Gueimonde, M., Sakata, S., Kalliomäki, M., Isolauri, E., Benno, Y., and Salminen, S. (2006). Effect of maternal consumption of lactobacillus GG on transfer and establishment of fecal bifidobacterial microbiota in neonates. J. .Pediatr. Gastroenterol. Nutr. 42, 166-170. doi: 10.1097/01.mpg.0000189346.25172.fd

Guellec, I., Lapillonne, A., Marret, S., Picaud, J.C., Mitanchez, D., Charkaluk, M.L., et al. (2016). Effect of intra- and extrauterine growth on long-term neurologic outcomes of very preterm infants. J. Pediatr. 175, 93-99. doi: 10.1016/j.jpeds. 2016.05.027

Harry, G.J. (2013). Microglia during development and aging. Pharmacol. Ther. 139(3), 313-326. doi: 10.1016/j.pharmthera.2013.04.013

Hascoët, J.M., Chauvin, M., Pierret, C., Skweres, S., Egroo, L.V., Rougé, C., et al. (2019). Impact of maternal nutrition and perinatal factors on breast milk composition after premature delivery. Nutrients 11:366. doi: 10.3390/ nu11020366

Hazlett, H. C., Poe, M., Gerig, G., Smith, R. G., Provenzale, J., Ross, A., et al. (2005). Magnetic resonance imaging and head circumference study of brain size in autism: birth through age 2 years. Arch. Gen. Psychiatry 62, 1366-1376. doi: 10.1001/archpsyc.62.12.1366

Hentges, D. J., Marsh, W. W., Petschow, B. W., Thal, W. R., and Carter, M. K. (1992). Influence of infant diets on the ecology of the intestinal tract of human flora-associated mice. J. Pediatr. Gastroenterol. Nutr. 14, 146-152. doi: 10.1097/ 00005176-199202000-00005

Hoban, A.E., Stilling, R.M., Ryan, F.J., Shanahan, F., Dinan, T.G., Claesson, M.J., et al. (2016). Regulation of prefrontal cortex myelination by the microbiota. Transl. Psychiatry 6:e774. doi: 10.1038/tp.2016.42

Hortensius, L.M., van Elburg, R.M., Nijboer, C.H., Benders, M., and de Theije, C.G.M. (2019). Postnatal nutrition to improve brain development in the preterm infant: a systematic review from bench to bedside. Front. Physiol. 10:961. doi: 10.3389/fphys.2019.00961

Hsu, Y.-C., Chen, C.-H., Lin, M.-C., Tsai, C.-R., Liang, J.-T., and Wang, T.-M. (2014). Changes in preterm breast milk nutrient content in the first month. Pediatr. Neonatol. 55, 449-454. doi: 10.1016/j.pedneo.2014.03.002

Hu, W., Zhao, J., Wang, J., Yu, T., Wang, J., and Li, N. (2012). Transgenic milk containing recombinant human lactoferrin modulates the intestinal flora in piglets. Biochem. Cell. Biol. 90, 485-496. doi: 10.1139/o2012-003

Huang, Z., and Hu, Y.M. (2020). Dietary patterns and their association with breast milk macronutrient composition among lactating women. Int. Breastfeed J. 15:52. doi: 10.1186/s13006-020-00293-w

Huttenlocher, P. R., and Dabholkar, A. S. (1997). Regional differences in synaptogenesis in human cerebral cortex. J. Comp. Neurol. 387, 167-178. doi: 10.1002/(sici)1096-9861(19971020)387:2<167::aid-cne1<3.0.co;2-z

Iizumi, T., Battaglia, T., Ruiz, V., and Perez Perez, G. I. (2017). Gut microbiome and antibiotics. Arch. Med. Res. 48, 727-734. doi: 10.1016/j.arcmed.2017.11.004

Jacobs, S.E., Hickey, L., Donath, S., Opie, G.F., Anderson, P.J., Garland, S.M., et al. (2017). Probiotics, prematurity and neurodevelopment: follow-up of a randomised trial. BMJ Paediatr. Open 1:e000176. doi: 10.1136/bmjpo-2017000176

Jakobsson, H. E., Abrahamsson, T. R., Jenmalm, M. C., Harris, K., Quince, C., Jernberg, C., et al. (2014). Decreased gut microbiota diversity, delayed Bacteroidetes colonisation and reduced Th1 responses in infants delivered by caesarean section. Gut 63, 559-566. doi: 10.1136/gutjnl-2012-303249

Jiang, T., Liu, B., Li, J., Dong, X., Lin, M., Zhang, M., et al. (2018). Association between sn-2 fatty acid profiles of breast milk and development of the infant intestinal microbiome. Food Funct. 9, 1028-1037. doi: 10.1039/c7fo00088j

Johnson, C.L., and Versalovic, J. (2012). The human microbiome and its potential importance to pediatrics. Pediatrics 129, 950-960. doi: 10.1542/peds.2011-2736

Joosten, K., Embleton, N., Yan, W., Senterre, T., and Espghan/Espen/Espr/Cspen Working Group On Pediatric Parenteral Nutrition. (2018).
ESPGHAN/ESPEN/ESPR/CSPEN guidelines on pediatric parenteral nutrition: Energy. Clin. Nutr. 37, 2309-2314. doi: 10.1016/j.clnu.2018.06.944

Jost, T., Lacroix, C., Braegger, C. P., and Chassard, C. (2012). New insights in gut microbiota establishment in healthy breast fed neonates. PLoS One 7:e44595. doi: 10.1371/journal.pone.0044595

Jost, T., Lacroix, C., Braegger, C., and Chassard, C. (2013). Assessment of bacterial diversity in breast milk using culture-dependent and culture-independent approaches. Br. J. Nutr. 110, 1253-1262. doi: 10.1017/S0007114513000597

Kamelska, A. M., Pietrzak-Fieæko, R., and Bryl, K. (2012). Variation of the cholesterol content in breast milk during 10 days collection at early stages of lactation. Acta Biochim. Pol. 59, 243-247.

Kapiki, A., Costalos, C., Oikonomidou, C., Triantafyllidou, A., Loukatou, E., and Pertrohilou, V. (2007). The effect of a fructo-oligosaccharide supplemented formula on gut flora of preterm infants. Early Hum. Dev. 83, 335-339. doi: 10.1016/j.earlhumdev.2006.07.003

Kaufman, D. A., Gurka, M. J., Hazen, K. C., Boyle, R., Robinson, M., and Grossman, L. B. (2006). Patterns of fungal colonization in preterm infants weighing less than 1000 grams at birth. Pediatr. Infect. Dis. J. 25, 733-737. doi: 10.1097/01.inf. 0000226978.96218.e6

Kaufman, D., Boyle, R., Hazen, K. C., Patrie, J. T., Robinson, M., and Donowitz, L. G. (2001). Fluconazole prophylaxis against fungal colonization and infection in preterm infants. N. Engl. J. Med. 345, 1660-1666. doi: 10.1056/ NEJMoa010494

Kelly, J. R., Minuto, C., Cryan, J. F., Clarke, G., and Dinan, T. G. (2017). Cross talk: the microbiota and neurodevelopmental disorders. Front. Neurosci. 11:490. doi: 10.3389/fnins.2017.00490

Kelly, M.S., Benjamin, D.K., Jr., and Smith, P.B. (2015). The epidemiology and diagnosis of invasive candidiasis among premature infants. Clin. Perinatol. 42, 105-117. doi: 10.1016/j.clp.2014.10.008

Knickmeyer, R.C., Gouttard, S., Kang, C., Evans, D., Wilber, K., Smith, J.K., et al. (2008). A structural MRI study of human brain development from birth to 2 years. J. Neurosci. 28, 12176-12182. doi: 10.1523/jneurosci.3479-08.2008

Knol, J., Scholtens, P., Kafka, C., Steenbakkers, J., Gro, S., Helm, K., et al. (2005). Colon microflora in infants fed formula with galacto- and fructooligosaccharides: more like breast-fed infants. J. Pediatr. Gastroenterol. Nutr. 40, 36-42. doi: 10.1097/00005176-200501000-00007

Koenig, J.E., Spor, A., Scalfone, N., Fricker, A.D., Stombaugh, J., Knight, R., et al. (2011). Succession of microbial consortia in the developing infant gut microbiome. Proc. Natl. Acad. Sci. U S A 108, 4578-4585. doi: 10.1073/pnas. 1000081107

Koletzko, B., Rodriguez-Palmero, M., Demmelmair, H., Fidler, N., Jensen, R., and Sauerwald, T. (2001). Physiological aspects of human milk lipids. Early Hum. Dev. 65, S3-S18. doi: 10.1016/s0378-3782(01)00204-3

Korpela, K., Blakstad, E.W., Moltu, S.J., Strømmen, K., Nakstad, B., Rønnestad, A.E., et al. (2018). Intestinal microbiota development and gestational age in preterm neonates. Sci. Rep. 8:2453. doi: 10.1038/s41598-018-20827-x

Koutsoumanis, K., Allende, A., Alvarez-Ordóñez, A., Bolton, D., Bover-Cid, S., Chemaly, M., et al. (2020). Scientific opinion on the update of the list of QPSrecommended biological agents intentionally added to food or feed as notified to EFSA (2017-2019). EFSA J. 18:e05966. doi: 10.2903/j.efsa.2020.5966

Kramer, M. S., Aboud, F., Mironova, E., Vanilovich, I., Platt, R. W., Matush, L., et al. (2008). Breastfeeding and child cognitive development: new evidence from a large randomized trial. Arch. Gen. Psychiatry 65, 578-584. doi: 10.1001/ archpsyc.65.5.578

Kumar, H., du Toit, E., Kulkarni, A., Aakko, J., Linderborg, K. M., Zhang, Y., et al. (2016). Distinct patterns in human milk microbiota and fatty acid profiles across specific geographic locations. Front. Microbiol. 7:1619. doi: 10.3389/ fmicb.2016.01619

Kunz, C., and Rudloff, S. (1993). Biological functions of oligosaccharides in human milk. Acta Paediatr. 82, 903-912. doi: 10.1111/j.1651-2227.1993.tb12597.x

Kunz, C., Meyer, C., Collado, M.C., Geiger, L., García-Mantrana, I., Bertua-Ríos, B., et al. (2017). Influence of gestational age, secretor, and lewis blood group status on the oligosaccharide content of human milk. J. Pediatr. Gastroenterol. Nutr. 64, 789-798. doi: 10.1097/mpg.0000000000001402

Kunz, C., Rodriquez-Palmero, M., Koletzko, B., and Jensen, R. (1999). Nutritional and biochemical properties of human milk, part I: general aspects, proteins, and carbohydrates. Clin. Perinatol. 26:307-333. doi: 10.1016/S0095-5108(18) 30055-1 
Kunz, C., Rudloff, S., Baier, W., Klein, N., and Strobel, S. (2000). Oligosaccharides in human milk: structural, functional, and metabolic aspects. Annu. Rev. Nutr. 20, 699-722. doi: 10.1146/annurev.nutr.20.1.699

La Rosa, P. S., Warner, B. B., Zhou, Y., Weinstock, G. M., Sodergren, E., HallMoore, C. M., et al. (2014). Patterned progression of bacterial populations in the premature infant gut. Proc Natl Acad Sci U S A 111, 12522-12527. doi: 10.1073/pnas.1409497111

Lackey, K.A., Williams, J.E., Meehan, C.L., Zachek, J.A., Benda, E.D., Price, W.J., et al. (2019). What's normal? microbiomes in human milk and infant feces are related to each other but vary geographically: The INSPIRE Study. Front. Nutr. 6:45. doi: $10.3389 /$ fnut. 2019.00045

Lagström, H., Rautava, S., Ollila, H., Kaljonen, A., Turta, O., Mäkelä, J., et al. (2020). Associations between human milk oligosaccharides and growth in infancy and early childhood. Am. J. Clin. Nutr. 111, 769-778. doi: 10.1093/ajcn/nqaa010

Lahtinen, S. J., Boyle, R. J., Kivivuori, S., Oppedisano, F., Smith, K. R., RobinsBrowne, R., et al. (2009). Prenatal probiotic administration can influence Bifidobacterium microbiota development in infants at high risk of allergy. J. Allergy Clin. Immunol. 123, 499-501. doi: 10.1016/j.jaci.2008.11.034

Lapillonne, A., Groh-Wargo, S., Gonzalez, C. H., and Uauy, R. (2013). Lipid needs of preterm infants: updated recommendations. J. Pediatr. 162, S37-S47. doi: 10.1016/j.jpeds.2012.11.052

LaTuga, M.S., Ellis, J.C., Cotton, C.M., Goldberg, R.N., Wynn, J.L., Jackson, R.B., et al. (2011). Beyond bacteria: a study of the enteric microbial consortium in extremely low birth weight infants. PLoS One 6:e27858. doi: 10.1371/journal. pone. 0027858

Lauder, A.P., Roche, A.M., Sherrill-Mix, S., Bailey, A., Laughlin, A.L., Bittinger, K., et al. (2016). Comparison of placenta samples with contamination controls does not provide evidence for a distinct placenta microbiota. Microbiome 4:29. doi: 10.1186/s40168-016-0172-3

Lavebratt, C., Yang, L.L., Giacobini, M., Forsell, Y., Schalling, M., Partonen, T., et al. (2019). Early exposure to antibiotic drugs and risk for psychiatric disorders: a population-based study. Transl. Psychiatry 9:317. doi: 10.1038/s41398-0190653-9

Le Huërou-Luron, I. L., Lemaire, M., and Blat, S. (2018). Health benefits of dairy lipids and MFGM in infant formula. OCL 25:D306.

Le Huerou-Luron, I., Bouzerzour, K., Ferret-Bernard, S., Menard, O., Le Normand, L., Perrier, C., et al. (2018). A mixture of milk and vegetable lipids in infant formula changes gut digestion, mucosal immunity and microbiota composition in neonatal piglets. Eur. J. Nutr. 57, 463-476. doi: 10.1007/s00394-016-1329-3

Leclercq, S., Mian, F.M., Stanisz, A.M., Bindels, L.B., Cambier, E., Ben-Amram, H., et al. (2017). Low-dose penicillin in early life induces long-term changes in murine gut microbiota, brain cytokines and behavior. Nat. Commun. 8:15062. doi: 10.1038/ncomms15062

Lee, H., Padhi, E., Hasegawa, Y., Larke, J., Parenti, M., Wang, A., et al. (2018). Compositional dynamics of the milk fat globule and its role in infant development. Front. Pediatr. 6:313. doi: 10.3389/fped.2018.00313

Lemaire, M., Le Huërou-Luron, I., and Blat, S. (2018). Effects of infant formula composition on long-term metabolic health. J. Dev. Orig. Health Dis. 9, 573589. doi: $10.1017 /$ S2040174417000964

Loughman, A., Ponsonby, A.L., O'Hely, M., Symeonides, C., Collier, F., Tang, M.L.K., et al. (2020). Gut microbiota composition during infancy and subsequent behavioural outcomes. EBioMedicine 52:102640. doi: 10.1016/j. ebiom.2020.102640

Lu, J., Synowiec, S., Lu, L., Yu, Y., Bretherick, T., Takada, S., et al. (2018). Microbiota influence the development of the brain and behaviors in C57BL/6J mice. PLoS One 13:e0201829. doi: 10.1371/journal.pone.0201829

Luczynski, P., McVey Neufeld, K.A., Oriach, C.S., Clarke, G., Dinan, T.G., and Cryan, J.F. (2016). Growing up in a Bubble: using germ-free animals to assess the influence of the gut microbiota on brain and behavior. Int. J. Neuropsychopharmacol. 19:yw020. doi: 10.1093/ijnp/pyw020

Lundgren, S.N., Madan, J.C., Emond, J.A., Morrison, H.G., Christensen, B.C., Karagas, M.R., et al. (2018). Maternal diet during pregnancy is related with the infant stool microbiome in a delivery mode-dependent manner. Microbiome 6:109. doi: 10.1186/s40168-018-0490-8

Luparia, M., Landi, F., Mesini, A., Militello, M.A., Galletto, P., Farina, D., et al. (2019). Fungal ecology in a tertiary neonatal intensive care unit after 16 years of routine fluconazole prophylaxis: no emergence of native fluconazole-resistant strains. Am. J. Perinatol. 36, 126-133. doi: 10.1055/s-0039-1691808
Lv, T., Ye, M., Luo, F., Hu, B., Wang, A., Chen, J., et al. (2021). Probiotics treatment improves cognitive impairment in patients and animals: A systematic review and meta-analysis. Neurosci. Biobehav. Rev. 120, 159-172. doi: 10.1016/ j.neubiorev.2020.10.027

Maas, C., Franz, A.R., Shunova, A., Mathes, M., Bleeker, C., Poets, C.F., et al. (2017). Choline and polyunsaturated fatty acids in preterm infants' maternal milk. Eur. J. Nutr. 56, 1733-1742. doi: 10.1007/s00394-016-1220-2

Mackie, R.I., Sghir, A., and Gaskins, H.R. (1999). Developmental microbial ecology of the neonatal gastrointestinal tract. Am. J. Clin. Nutr. 69, 1035-1045. doi: 10.1093/ajcn/69.5.1035s

Majnik, A. V., and Lane, R. H. (2015). The relationship between early-life environment, the epigenome and the microbiota. Epigenomics 7, 1173-1184. doi: $10.2217 /$ epi.15.74

Makino, H., Kushiro, A., Ishikawa, E., Kubota, H., Gawad, A., Sakai, T., et al. (2013). Mother-to-infant transmission of intestinal bifidobacterial strains has an impact on the early development of vaginally delivered infant's microbiota. PLoS One 8:e78331. doi: 10.1371/journal.pone.0078331

Mantis, N.J., Rol, N., and Corthésy, B. (2011). Secretory IgA's complex roles in immunity and mucosal homeostasis in the gut. Mucosal. Immunol. 4, 603-611. doi: $10.1038 / \mathrm{mi} .2011 .41$

Manzoni, P., Mostert, M., and Castagnola, E. (2015). Update on the management of Candida infections in preterm neonates. Arch. Dis. Child Fetal. Neonatal. Ed. 100, F454-F459. doi: 10.1136/archdischild-2012-303350

Marcobal, A., Barboza, M., Sonnenburg, E.D., Pudlo, N., Martens, E.C., Desai, P., et al. (2011). Bacteroides in the infant gut consume milk oligosaccharides via mucus-utilization pathways. Cell Host. Microbe 10, 507-514. doi: 10.1016/j. chom.2011.10.007

Mastromarino, P., Capobianco, D., Campagna, G., Laforgia, N., Drimaco, P., Dileone, A., et al. (2014). Correlation between lactoferrin and beneficial microbiota in breast milk and infant's feces. Biometals 27, 1077-1086. doi: 10.1007/s10534-014-9762-3

Mayer, E. A., Knight, R., Mazmanian, S. K., Cryan, J. F., and Tillisch, K. (2014). Gut microbes and the brain: paradigm shift in neuroscience. J. Neurosci. 34, 15490-15496. doi: 10.1523/jneurosci.3299-14.2014

Mazurier, E., Rigourd, V., Perez, P., Buffin, R., Couedelo, L., Vaysse, C., et al. (2017). Effects of maternal supplementation with omega-3 Precursors on human milk composition. J. Hum. Lact. 33, 319-328. doi: 10.1177/0890334417691 946

Mazzocchi, A., D’Oria, V., De Cosmi, V., Bettocchi, S., Milani, G.P., Silano, M., et al. (2018). The role of lipids in human milk and infant formulae. Nutrients 10:567. doi: 10.3390/nu10050567

Montagne, P., Cuillière, M. L., Molé, C., Béné, M. C., and Faure, G. (1999). Immunological and nutritional composition of human milk in relation to prematurity and Mothers' Parity during the first 2 weeks of lactation. J. Pediatr. Gastroenterol. Nutr. 29, 75-80.

Moro, G.E., Arslanoglu, S., Bertino, E., Corvaglia, L., Montirosso, R., Picaud, J.C., et al. (2015). XII. Human milk in feeding premature infants: consensus statement. J. Pediatr. Gastroenterol. Nutr. 61, S16-S19. doi: 10.1097/01.mpg. $0000471460.08792 .4 \mathrm{~d}$

Morowitz, M. J., Denef, V. J., Costello, E. K., Thomas, B. C., Poroyko, V., Relman, D. A., et al. (2011). Strain-resolved community genomic analysis of gut microbial colonization in a premature infant. Proc. Natl. Acad. Sci. U S A 108, 1128-1133. doi: 10.1073/pnas.1010992108

Mueller, N. T., Bakacs, E., Combellick, J., Grigoryan, Z., and Dominguez-Bello, M. G. (2015). The infant microbiome development: mom matters. Trends Mol. Med. 21, 109-117. doi: 10.1016/j.molmed.2014.12.002

Musilova, S., Rada, V., Vlkova, E., and Bunesova, V. (2014). Beneficial effects of human milk oligosaccharides on gut microbiota. Benef. Microb. 5, 273-283. doi: $10.3920 / \mathrm{bm} 2013.0080$

Nagata, R., Nagano, H., Ogishima, D., Nakamura, Y., Hiruma, M., and Sugita, T. (2012). Transmission of the major skin microbiota, Malassezia, from mother to neonate. Pediatr. Int. 54, 350-355. doi: 10.1111/j.1442-200X.2012.03563.x

Nakhla, T., Fu, D., Zopf, D., Brodsky, N. L., and Hurt, H. (1999). Neutral oligosaccharide content of preterm human milk. Br. J. Nutr. 82, 361-367. doi: 10.1017/S0007114599001609

Nejrup, R.G., Bahl, M.I., Vigsnæs, L.K., Heerup, C., Licht, T.R., and Hellgren, L.I. (2015). Lipid hydrolysis products affect the composition of infant gut microbial communities in vitro. Br. J. Nutr. 114, 63-74. doi: 10.1017/s0007114515000811 
Nejrup, R.G., Licht, T.R., and Hellgren, L.I. (2017). Fatty acid composition and phospholipid types used in infant formulas modifies the establishment of human gut bacteria in germ-free mice. Sci. Rep. 7:3975. doi: 10.1038/s41598017-04298-0

Nguyen, T. N., Spencer-Smith, M., Zannino, D., Burnett, A., Scratch, S. E., Pascoe, L., et al. (2018). Developmental Trajectory of Language From 2 to 13 Years in Children Born Very Preterm. Pediatrics 141:e20172831. doi: 10.1542/peds. 2017-2831

Ogbonnaya, E. S., Clarke, G., Shanahan, F., Dinan, T. G., Cryan, J. F., and O'Leary, O. F. (2015). Adult hippocampal neurogenesis is regulated by the microbiome. Biol. Psychiatry 78, e7-e9. doi: 10.1016/j.biopsych.2014.12.023

Oikonomou, G., Addis, M. F., Chassard, C., Nader-Macias, M. E. F., Grant, I., Delbès, C., et al. (2020). Milk microbiota: what are we exactly talking about? Front. Microbiol. 11:60. doi: 10.3389/fmicb.2020.00060

O’Mahony, S. M., Felice, V. D., Nally, K., Savignac, H. M., Claesson, M. J., Scully, P., et al. (2014). Disturbance of the gut microbiota in early-life selectively affects visceral pain in adulthood without impacting cognitive or anxiety-related behaviors in male rats. Neuroscience 277, 885-901. doi: 10.1016/j.neuroscience. 2014.07.054

Oozeer, R., van Limpt, K., Ludwig, T., Ben Amor, K., Martin, R., Wind, R.D., et al. (2013). Intestinal microbiology in early life: specific prebiotics can have similar functionalities as human-milk oligosaccharides. Am. J. Clin. Nutr. 98(2), 561-571. doi: 10.3945/ajcn.112.038893

O'Sullivan, A., Farver, M., and Smilowitz, J.T. (2015). The influence of early infantfeeding practices on the intestinal microbiome and body composition in infants. Nutr. Metab. Insights 8, 1-9. doi: 10.4137/nmi.S29530

Palmer, C., Bik, E. M., DiGiulio, D. B., Relman, D. A., and Brown, P. O. (2007). Development of the human infant intestinal microbiota. PLoS Biol. 5:e177. doi: 10.1371/journal.pbio.0050177

Parra-Llorca, A., Gormaz, M., Alcántara, C., Cernada, M., Nuñez-Ramiro, A., Vento, M., et al. (2018). Preterm gut microbiome depending on feeding type: significance of donor human milk. Front. Microbiol. 9:1376. doi: 10.3389/fmicb. 2018.01376

Penders, J., Thijs, C., Vink, C., Stelma, F. F., Snijders, B., Kummeling, I., et al. (2006). Factors influencing the composition of the intestinal microbiota in early infancy. Pediatrics 118, 511-521. doi: 10.1542/peds.20052824

Peng, L., Li, Z. R., Green, R. S., Holzman, I. R., and Lin, J. (2009). Butyrate enhances the intestinal barrier by facilitating tight junction assembly via activation of AMP-activated protein kinase in Caco-2 cell monolayers. J. Nutr. 139, 16191625. doi: $10.3945 /$ jn. 109.104638

Pérez-Cobas, A.E., Artacho, A., Knecht, H., Ferrús, M.L., Friedrichs, A., Ott, S.J., et al. (2013). Differential effects of antibiotic therapy on the structure and function of human gut microbiota. PLoS One 8:e80201. doi: 10.1371/journal. pone. 0080201

Perez-Muñoz, M.E., Arrieta, M.C., Ramer-Tait, A.E., and Walter, J. (2017). A critical assessment of the "sterile womb" and "in utero colonization" hypotheses: implications for research on the pioneer infant microbiome. Microbiome 5:48. doi: 10.1186/s40168-017-0268-4

Perrone, S., Longini, M., Zollino, I., Bazzini, F., Tassini, M., Vivi, A., et al. (2019). Breast milk: To each his own. From metabolomic study, evidence of personalized nutrition in preterm infants. Nutrition 62, 158-161. doi: 10.1016/ j.nut.2018.12.015

Petanjek, Z., Judas, M., Kostoviæ, I., and Uylings, H.B. (2008). Lifespan alterations of basal dendritic trees of pyramidal neurons in the human prefrontal cortex: a layer-specific pattern. Cereb. Cortex 18, 915-929. doi: 10.1093/cercor/bhm124

Pierrat, V., Burguet, A., Marchand-Martin, L., Cambonie, G., Coquelin, A., Roze, J.C., et al. (2020). Variations in patterns of care across neonatal units and their associations with outcomes in very preterm infants: the French EPIPAGE-2 cohort study. BMJ Open 10:e035075. doi: 10.1136/bmjopen-2019-0 35075

Pierrat, V., Marchand-Martin, L., Arnaud, C., Kaminski, M., Resche-Rigon, M., Lebeaux, C., et al. (2017). Neurodevelopmental outcome at 2 years for preterm children born at 22 to 34 weeks' gestation in France in 2011: EPIPAGE-2 cohort study. BMJ 358:j3448. doi: 10.1136/bmj.j3448

Plaza-Zamora, J., Sabater-Molina, M., Rodríguez-Palmero, M., Rivero, M., Bosch, V., Nadal, J. M., et al. (2013). Polyamines in human breast milk for preterm and term infants. Br. J. Nutr. 110, 524-528. doi: 10.1017/s0007114512005284
Premkumar, M.H., Pammi, M., and Suresh, G. (2019). Human milk-derived fortifier versus bovine milk-derived fortifier for prevention of mortality and morbidity in preterm neonates. Cochrane Database Syst. Rev. 2019:CD013145. doi: 10.1002/14651858.CD013145.pub2

Quigley, M., Embleton, N. D., and McGuire, W. (2019). Formula versus donor breast milk for feeding preterm or low birth weight infants. Cochrane Database Syst. Rev. 7:Cd002971. doi: 10.1002/14651858.CD002971.pub5

Quigley, M.A., Hockley, C., Carson, C., Kelly, Y., Renfrew, M.J., and Sacker, A. (2012). Breastfeeding is associated with improved child cognitive development: a population-based cohort study. J. Pediatr. 160, 25-32. doi: 10.1016/j.jpeds. 2011.06.035

Rinne, M. M., Gueimonde, M., Kalliomäki, M., Hoppu, U., Salminen, S. J., and Isolauri, E. (2005). Similar bifidogenic effects of prebiotic-supplemented partially hydrolyzed infant formula and breastfeeding on infant gut microbiota. FEMS Immunol. Med. Microbiol. 43, 59-65. doi: 10.1016/j.femsim.2004.07.005

Roberfroid, M., Gibson, G. R., Hoyles, L., McCartney, A. L., Rastall, R., Rowland, I., et al. (2010). Prebiotic effects: metabolic and health benefits. Br. J. Nutr. 104, S1-S63. doi: 10.1017/s0007114510003363

Roberts, A. K., Chierici, R., Sawatzki, G., Hill, M. J., Volpato, S., and Vigi, V. (1992). Supplementation of an adapted formula with bovine lactoferrin: 1. Effect on the infant faecal flora. Acta Paediatr. 81, 119-14doi: 10.1111/j.1651-2227.1992. tb12186.x

Robinson, A., Fiechtner, L., Roche, B., Ajami, N. J., Petrosino, J. F., Camargo, C. A. Jr., et al. (2017). Association of maternal gestational weight gain with the infant fecal microbiota. J. Pediatr. Gastroenterol. Nutr. 65, 509-515. doi: 10.1097/mpg.0000000000001566

Roger, L.C., Costabile, A., Holland, D.T., Hoyles, L., and McCartney, A.L. (2010). Examination of faecal Bifidobacterium populations in breast- and formulafed infants during the first 18 months of life. Microbiology 156, 3329-3341. doi: 10.1099/mic.0.043224-0

Romeo, M.G., Romeo, D.M., Trovato, L., Oliveri, S., Palermo, F., Cota, F., et al. (2011). Role of probiotics in the prevention of the enteric colonization by Candida in preterm newborns: incidence of late-onset sepsis and neurological outcome. J. Perinatol. 31, 63-69. doi: 10.1038/jp.2010.57

Rozé, J.C., Ancel, P.Y., Lepage, P., Martin-Marchand, L., Al Nabhani, Z., Delannoy, J., et al. (2017). Nutritional strategies and gut microbiota composition as risk factors for necrotizing enterocolitis in very-preterm infants. Am. J. Clin. Nutr. 106, 821-830. doi: 10.3945/ajcn.117.152967

Rozé, J.C., Ancel, P.Y., Marchand-Martin, L., Rousseau, C., Montassier, E., Monot, C., et al. (2020). Assessment of neonatal intensive care unit practices and preterm newborn gut microbiota and 2-Year neurodevelopmental outcomes. JAMA Netw. Open 3:e2018119. doi: 10.1001/jamanetworkopen.2020. 18119

Saben, J.L., Sims, C.R., Piccolo, B.D., and Andres, A. (2020). Maternal adiposity alters the human milk metabolome: associations between nonglucose monosaccharides and infant adiposity. Am. J. Clin. Nutr. 112, 1228-1239. doi: 10.1093/ajcn/nqaa216

Saigal, S., and Doyle, L. W. (2008). An overview of mortality and sequelae of preterm birth from infancy to adulthood. Lancet 371, 261-269. doi: 10.1016/ S0140-6736(08)60136-1

Salter, S. J., Cox, M. J., Turek, E. M., Calus, S. T., Cookson, W. O., Moffatt, M. F., et al. (2014). Reagent and laboratory contamination can critically impact sequence-based microbiome analyses. BMC Biol. 12:87. doi: 10.1186/s12915014-0087-z

Sámano, R., Martínez-Rojano, H., Hernández, R.M., Ramírez, C., Flores Quijano, M.E., Espíndola-Polis, J.M., et al. (2017). Retinol and $\alpha$-tocopherol in the breast milk of women after a high-risk pregnancy. Nutrients 9:14. doi: 10.3390/ nu9010014

Samuel, T.M., Binia, A., de Castro, C.A., Thakkar, S.K., Billeaud, C., Agosti, M., et al. (2019). Impact of maternal characteristics on human milk oligosaccharide composition over the first 4 months of lactation in a cohort of healthy European mothers. Sci. Rep. 9:11767. doi: 10.1038/s41598-019-48337-4

Sari, F. N., Eras, Z., Dizdar, E. A., Erdeve, O., Oguz, S. S., Uras, N., et al. (2012). Do oral probiotics affect growth and neurodevelopmental outcomes in very low-birth-weight preterm infants? Am. J. Perinatol. 29, 579-586. doi: 10.1055/ s-0032-1311981

Sawada, N., Kotani, T., Konno, T., Setiawan, J., Nishigaito, Y., Saito, Y., et al. (2018). Regulation by commensal bacteria of neurogenesis in the subventricular 
zone of adult mouse brain. Biochem. Biophys. Res. Commun. 498, 824-829. doi: 10.1016/j.bbrc.2018.03.064

Scalabrin, D. M., Mitmesser, S. H., Welling, G. W., Harris, C. L., Marunycz, J. D., Walker, D. C., et al. (2012). New prebiotic blend of polydextrose and galacto-oligosaccharides has a bifidogenic effect in young infants. J. Pediatr. Gastroenterol. Nutr. 54, 343-352. doi: 10.1097/MPG.0b013e318237e d95

Schneider, J., Fischer Fumeaux, C.J., Duerden, E.G., Guo, T., Foong, J., Graz, M.B., et al. (2018). Nutrient intake in the first two weeks of life and brain growth in preterm neonates. Pediatrics 141: doi: 10.1542/peds.2017-2169

Schneider, N., and Garcia-Rodenas, C. L. (2017). Early nutritional interventions for brain and cognitive development in preterm infants: a review of the literature. Nutrients 9:187. doi: 10.3390/nu9030187

Schwiertz, A., Gruhl, B., Löbnitz, M., Michel, P., Radke, M., and Blaut, M. (2003). Development of the intestinal bacterial composition in hospitalized preterm infants in comparison with breast-fed, full-term infants. Pediatr. Res. 54, 393-399. doi: 10.1203/01.Pdr.0000078274.74607.7a

Seppo, A.E., Kukkonen, A.K., Kuitunen, M., Savilahti, E., Yonemitsu, C., Bode, L., et al. (2019). Association of Maternal probiotic supplementation with human milk Oligosaccharide composition. JAMA Pediatr. 173, 286-288. doi: 10.1001/ jamapediatrics.2018.4835

Sharon, G., Sampson, T.R., Geschwind, D.H., and Mazmanian, S.K. (2016). The central nervous system and the gut microbiome. Cell 167, 915-932. doi: 10. 1016/j.cell.2016.10.027

Shoji, H., Shimizu, T., Kaneko, N., Shinohara, K., Shiga, S., Saito, M., et al. (2006). Comparison of the phospholipid classes in human milk in Japanese mothers of term and preterm infants. Acta Paediatr. 95, 996-1000. doi: 10.1080/ 08035250600660933

Sierra, C., Bernal, M.J., Blasco, J., Martínez, R., Dalmau, J., Ortuño, I., et al. (2015). Prebiotic effect during the first year of life in healthy infants fed formula containing GOS as the only prebiotic: a multicentre, randomised, double-blind and placebo-controlled trial. Eur. J. Nutr. 54, 89-99. doi: 10.1007/s00394-0140689-9

Simpson, J. H., McKerracher, L., Cooper, A., Barnett, D., Gentles, E., Cairns, L., et al. (2016). Optimal distribution and utilization of donated human breast milk. J. Hum. Lact. 32, 730-734. doi: 10.1177/0890334416653738

Slykerman, R. F., Thompson, J., Waldie, K. E., Murphy, R., Wall, C., and Mitchell, E. A. (2017). Antibiotics in the first year of life and subsequent neurocognitive outcomes. Acta Paediatr. 106, 87-94. doi: 10.1111/apa. 13613

Slykerman, R.F., Coomarasamy, C., Wickens, K., Thompson, J.M.D., Stanley, T.V., Barthow, C., et al. (2019). Exposure to antibiotics in the first 24 months of life and neurocognitive outcomes at 11 years of age. Psychopharmacology 236, 1573-1582. doi: 10.1007/s00213-019-05216-0

Sordillo, J.E., Korrick, S., Laranjo, N., Carey, V., Weinstock, G.M., Gold, D.R., et al. (2019). Association of the infant gut microbiome with early childhood neurodevelopmental outcomes: an ancillary study to the VDAART Randomized Clinical Trial. JAMA Netw Open 2:e190905. doi: 10.1001/ jamanetworkopen.2019.0905

Spevacek, A.R., Smilowitz, J.T., Chin, E.L., Underwood, M.A., German, J.B., and Slupsky, C.M. (2015). Infant maturity at birth reveals minor differences in the maternal milk metabolome in the first month of lactation. J. Nutr. 145, 1698-1708. doi: 10.3945/jn.115.210252

Sprong, R. C., Hulstein, M. F., and Van der Meer, R. (2001). Bactericidal activities of milk lipids. Antimicrob. Agents Chemother. 45, 1298-1301. doi: 10.1128/aac. 45.4.1298-1301.2001

Stilling, R. M., Moloney, G. M., Ryan, F. J., Hoban, A. E., Bastiaanssen, T. F., Shanahan, F., et al. (2018). Social interaction-induced activation of RNA splicing in the amygdala of microbiome-deficient mice. Elife 7:e33070. doi: 10.7554/eLife.33070

Stilling, R.M., Dinan, T.G., and Cryan, J.F. (2014). Microbial genes, brain \& behaviour - epigenetic regulation of the gut-brain axis. Genes Brain Behav. 13, 69-86. doi: 10.1111/gbb.12109

Strøm, M., Mortensen, E. L., Kesmodel, U. S., Halldorsson, T., Olsen, J., and Olsen, S. F. (2019). Is breast feeding associated with offspring IQ at age 5? Findings from prospective cohort: lifestyle during pregnancy study. BMJ Open 9:e023134. doi: 10.1136/bmjopen-2018-023134
Sundekilde, U. K., Downey, E., O'Mahony, J. A., O’Shea, C. A., Ryan, C. A., Kelly, A. L., et al. (2016). The effect of gestational and lactational age on the human milk metabolome. Nutrients 8:304. doi: 10.3390/nu8050 304

Tanaka, K., Hosozawa, M., Kudo, N., Yoshikawa, N., Hisata, K., Shoji, H., et al. (2013). The pilot study: sphingomyelin-fortified milk has a positive association with the neurobehavioural development of very low birth weight infants during infancy, randomized control trial. Brain Dev. 35, 45-52. doi: 10.1016/j.braindev. 2012.03.004

Timby, N., Domellöf, E., Hernell, O., Lönnerdal, B., and Domellöf, M. (2014). Neurodevelopment, nutrition, and growth until 12 mo of age in infants fed a low-energy, low-protein formula supplemented with bovine milk fat globule membranes: a randomized controlled trial. Am. J. Clin. Nutr. 99, 860-868. doi: 10.3945/ajen.113.064295

Timby, N., Domellöf, M., Holgerson, P. L., West, C. E., Lönnerdal, B., Hernell, O., et al. (2017a). Oral microbiota in infants fed a formula supplemented with bovine milk fat globule membranes - a randomized controlled trial. PLoS One 12:e0169831. doi: 10.1371/journal.pone.0169831

Timby, N., Domellof, M., Lonnerdal, B., and Hernell, O. (2017b). Supplementation of infant formula with bovine milk fat globule membranes. Adv. Nutr. 8, 351-355. doi: 10.3945/an.116.014142

Tolhurst, G., Heffron, H., Lam, Y. S., Parker, H. E., Habib, A. M., Diakogiannaki, E., et al. (2012). Short-chain fatty acids stimulate glucagon-like peptide-1 secretion via the G-protein-coupled receptor FFAR2. Diabetes 61, 364-371. doi: 10.2337/ db11-1019

Tomova, A., Husarova, V., Lakatosova, S., Bakos, J., Vlkova, B., Babinska, K., et al. (2015). Gastrointestinal microbiota in children with autism in Slovakia. Physiol. Behav. 138, 179-187. doi: 10.1016/j.physbeh.2014.10.033

Tudehope, D.I. (2013). Human milk and the nutritional needs of preterm infants. J. Pediatr. 162, S17-S25. doi: 10.1016/j.jpeds.2012.11.049

Underwood, M.A., Gaerlan, S., De Leoz, M.L., Dimapasoc, L., Kalanetra, K.M., Lemay, D.G., et al. (2015). Human milk oligosaccharides in premature infants: absorption, excretion, and influence on the intestinal microbiota. Pediatr. Res. 78, 670-677. doi: 10.1038/pr.2015.162

Urbaniak, C., Angelini, M., Gloor, G.B., and Reid, G. (2016). Human milk microbiota profiles in relation to birthing method, gestation and infant gender. Microbiome 4:1. doi: 10.1186/s40168-015-0145-y

van Beek, P. E., Claessens, N. H. P., Makropoulos, A., Groenendaal, F., de Vries, L. S., Counsell, S. J., et al. (2020). Increase in brain volumes after implementation of a nutrition regimen in infants born extremely preterm. J. Pediatr. 223, 57-63. doi: 10.1016/j.jpeds.2020.04.063

van den Berg, J. P., Westerbeek, E. A., Bröring-Starre, T., Garssen, J., and van Elburg, R. M. (2016). Neurodevelopment of Preterm Infants at 24 Months After Neonatal Supplementation of a Prebiotic Mix: A Randomized Trial. J. Pediatr. Gastroenterol. Nutr. 63, 270-276. doi: 10.1097/mpg.0000000000001148

Van Lieshout, R.J. (2013). Role of maternal adiposity prior to and during pregnancy in cognitive and psychiatric problems in offspring. Nutr. Rev. 71, S95-S101. doi: 10.1111/nure.12059

van Noort-van der Spek, I.L., Franken, M.-C.J.P., and Weisglas-Kuperus, N. (2012). Language Functions in Preterm-Born Children: A Systematic Review and Meta-analysis. Pediatrics 129, 745-754. doi: 10.1542/peds.2011-1728

Vandenplas, Y., Zakharova, I., and Dmitrieva, Y. (2015). Oligosaccharides in infant formula: more evidence to validate the role of prebiotics. Br. J. Nutr. 113, 1339-1344. doi: 10.1017/s0007114515000823

Wandro, S., Osborne, S., Enriquez, C., Bixby, C., Arrieta, A., and Whiteson, K. (2018). The microbiome and metabolome of preterm infant stool are personalized and not driven by health outcomes, including necrotizing enterocolitis and late-onset sepsis. mSphere 3, e00104-18. doi: 10.1128/ mSphere.00104-18

Wassenaar, T. M., and Panigrahi, P. (2014). Is a foetus developing in a sterile environment? Lett. Appl .Microbiol. 59, 572-579. doi: 10.1111/lam.12334

World Health Organization (2011). Guidelines on Optimal Feeding of Low BirthWeight Infants in Low-and Middle-Income Countries [Internet]. Geneva: WHO.

Yaron, S., Shachar, D., Abramas, L., Riskin, A., Bader, D., Litmanovitz, I., et al. (2013). Effect of high $\beta$-palmitate content in infant formula on the intestinal microbiota of term infants. J. Pediatr. Gastroenterol. Nutr. 56, 376-381. doi: 10.1097/MPG.0b013e31827e1ee2 
Yassour, M., Vatanen, T., Siljander, H., Hämäläinen, A.M., Härkönen, T., Ryhänen, S.J., et al. (2016). Natural history of the infant gut microbiome and impact of antibiotic treatment on bacterial strain diversity and stability. Sci. Transl. Med. 8:343ra381. doi: 10.1126/scitranslmed.aad0917

Yatsunenko, T., Rey, F. E., Manary, M. J., Trehan, I., Dominguez-Bello, M. G., Contreras, M., et al. (2012). Human gut microbiome viewed across age and geography. Nature 486, 222-227. doi: 10.1038/nature11053

Zanella, A., Silveira, R. C., Roesch, L. F. W., Corso, A. L., Dobbler, P. T., Mai, V., et al. (2019). Influence of own mother's milk and different proportions of formula on intestinal microbiota of very preterm newborns. PLoS One 14:e0217296. doi: 10.1371/journal.pone.0217296

Zentek, J., Buchheit-Renko, S., Männer, K., Pieper, R., and Vahjen, W. (2012). Intestinal concentrations of free and encapsulated dietary medium-chain fatty acids and effects on gastric microbial ecology and bacterial metabolic products in the digestive tract of piglets. Arch. Anim. Nutr. 66, 14-26. doi: 10.1080/ 1745039x.2011.644916

Zhao, X., Xu, Z., Wang, Y., and Sun, Y. (1989). [Studies of the relation between the nutritional status of lactating mothers and milk composition as well as the milk intake and growth of their infants in Beijing. Pt. 4. The protein and amino acid content of breast milk]. Ying Yang Xue Bao 11, 227-232.
Zhou, C., Rao, X., Wang, H., Zeng, B., Yu, Y., Chen, J., et al. (2019). Hippocampusspecific regulation of long non-coding RNA and mRNA expression in germfree mice. Funct. Integr. Genom. 20, 355-365. doi: 10.1007/s10142-01900716-w

Ziegler, E. E. (2011). Meeting the nutritional needs of the low-birth-weight infant. Ann. Nutr. Metab. 58, 8-18. doi: 10.1159/000323381

Ziegler, E.E. (2014). Human milk and human milk fortifiers. World Rev. Nutr. Diet 110, 215-227. doi: 10.1159/000358470

Conflict of Interest: The authors declare that the research was conducted in the absence of any commercial or financial relationships that could be construed as a potential conflict of interest.

Copyright (c) 2021 Buffet-Bataillon, Bellanger, Boudry, Gangneux, Yverneau, Beuchée, Blat and Le Huërou-Luron. This is an open-access article distributed under the terms of the Creative Commons Attribution License (CC BY). The use, distribution or reproduction in other forums is permitted, provided the original author(s) and the copyright owner(s) are credited and that the original publication in this journal is cited, in accordance with accepted academic practice. No use, distribution or reproduction is permitted which does not comply with these terms. 